\title{
Comprehensive study of the phenolic composition of the edible parts of jambolan fruit (Syzygium cumini (L.) Skeels)
}

\author{
Iasnaia Maria de Carvalho Tavares ${ }^{a}$, Ellen Silva Lago-Vanzela ${ }^{a}$, Ligia Portugal Gomes Rebello ${ }^{\text {, }}$ \\ Afonso Mota Ramos ${ }^{\text {c }}$, Sergio Gómez-Alonso ${ }^{\mathrm{d}, \mathrm{e}}$, Esteban García-Romero ${ }^{\mathrm{f}}$, \\ Roberto Da-Silva ${ }^{a}$, Isidro Hermosín-Gutiérrez ${ }^{\mathrm{d}, *}$ \\ a Instituto de Biociências, Letras e Ciências Exatas, Universidade Estadual Paulista, Cristovão Colombo, 2265, Jardim Nazareth, 15054-000 São José do Rio Preto, São Paulo, Brazil \\ ${ }^{\mathrm{b}}$ Instituto Federal Fluminense, Avenida Dário Vieira Borges 235, 28360-000 Bom Jesus do Itabapoana, Brazil \\ c Universidade Federal de Viçosa, Avenida Peter Henry Rolfs, s/n, Campus Universitário, 36570-000 Viçosa, Minas Gerais, Brazil \\ d Universidad de Castilla-La Mancha, Instituto Regional de Investigación Científica Aplicada, Avda. Camilo José Cela s/n, 13071 Ciudad Real, Spain \\ e Fundación Parque Científico y Tecnológico de Castilla-La Mancha, Paseo de la Innovación, 1, 02006 Albacete, Spain \\ ${ }^{\mathrm{f}}$ Instituto de la Vid y el Vino de Castilla-La Mancha, Carretera de Albacete s/n, 13700 Tomelloso, Spain
}

\section{A R T I C L E I N F O}

\section{Article history:}

Received 22 September 2015

Received in revised form 6 January 2016

Accepted 15 January 2016

Available online 18 January 2016

\section{Keywords:}

Jambolan

Anthocyanins

Flavonols

Flavanonols

Flavan-3-ols

Proanthocyanidins

Hydrolyzable tannins

\begin{abstract}
A B S T R A C T
Jambolan fruit has been used in traditional Indian medicine and has recently attracted interest as a functional food. The comprehensive study by HPLC-DAD-ESI-MS/MS has revealed the occurrence of around 74 individual phenolic compounds in the edible parts of jambolan, including 9 anthocyanins (mainly based on delphinidin, petunidin and malvidin), 9 flavonols (myricetin, laricitrin and syringetin glycosides), 19 flavanonols (dihexosides of dihydromyricetin and its methylated derivatives), 8 flavan-3-ol monomers (mainly gallocatechin), 13 gallotanins and 13 ellagitanins, together with some proanthocyanidins (highly galloylated prodelphinidins) and free gallic and ellagic acids. No hydroxycinnamic acid derivatives were detected. The skin of the jambolan fruit accumulated great amounts of phenolic compounds, almost all of the non-tannin phenolics. In contrast, condensed tannins (proanthocyanidins) and hydrolyzable tannins (gallotannins and ellagitannins) were present in both edible parts, accounting for greater amounts in the skin. Overall, the main phenolics of jambolan were anthocyanins and hydrolyzable tannins (similar amounts of gallotannins and ellagitanins), followed by flavanonols, flavonols and flavan-3-ols.
\end{abstract}

(c) 2016 Elsevier Ltd. All rights reserved.

\section{Introduction}

Jambolan (Syzygium cumini (L.) Skeels; Syn.: Eugenia jambolana Lamarck, and Eugenia cumini (L.) Druce; Family: Myrtaceae), also known as jambolão, jamblon, jambul, jamelão, jamun, jamman, Indian black plum, or Java plum is the edible fruit of a widespread tropical tree, native to India, that is commonly found nowadays in different regions of Brazil as an ornamental tree. The jambolan fruit looks like a black olive with only one, big, purple seed and it has a sour taste. In India, jambolan has a long history of use in the treatment of various diseases (Ayyanar \& Subash-Babu, 2012; Baliga, Bhat, Baliga, Wilson, \& Palatty, 2011; Sah \& Verma, 2011; Rodrigues et al., 2015; Sari, Setiawan, \& Siswoyo, 2015) especially diabetes (Helmstädter, 2008; Kumar et al., 2008; Tupe et al., 2015). Moreover, there is an increasing interest in the inclusion of jambolan in the human diet as a fresh fruit and also as prepared foods like health juice (Swami, Thakor, Patil, \& Haldankar, 2012), jam (Lago, Gomes, \& Da-Silva, 2006; Lago-Vanzela, Santos,

\footnotetext{
* Corresponding author.

E-mail address: isidro.hermosin@uclm.es (I. Hermosín-Gutiérrez).
}

Lima, Gomes \& Silva, 2011), pulp (Aqil, Gupta, Munagala, Jeyabalan, \& Kausar, 2012), frozen yoghurt (Bezerra, Araujo, Santos, \& Correia, 2015), muffins (Singh, Kaur, Shevkani, \& Singh, 2015), seed powder (Sheikh, Shahnawaz, Nizamani, Bhanger, \& Ahmed, 2011), wine (Nuengchamnong \& Ingkaninan, 2009), spray-dried extracts from its seeds (Peixoto \& Freitas, 2013), spray-dried fruit juice powder (Santhalakshmy, Don Bosco, Francis, \& Sabeena, 2015), freeze-dried fruit (Santana et al., 2015) and powder obtained by drying residue from peel and seeds in a spouted bed (Mussi, Guimarães, Ferreira, \& Pereira, 2015).

The potential of the extracts of this fruit as an antioxidant additive (Sheikh et al., 2011; Tobal, Da-Silva, Gomes, Bolini, \& Boscolo, 2012) and as a source of natural coloring for food (Sari, Wijaya, Sajuthi, \& Suprat, 2012) has been demonstrated. In addition, other potential biological activities of jambolan have been highlighted, like its antioxidant capacity (Aruna, Prakasha, Abrahamb, \& Premkumara, 2011; Hassimotto, Genovese, \& Lajolo, 2005; Rufino, Alves, Fernandes, \& Brito, 2011; Veigas, Narayan, Laxman, \& Neelwarne, 2007), antiinflammatory properties (Pavan Kumar, Prasad, Rao, Reddy, \& Abhinay, 2010), antibacterial properties (Kaneria, Chanda, Baravalia, \& 
Vaghasiya, 2009; Migliato et al., 2010), antiproliferative activities against human lung cancer A549 cells (Aqil et al., 2012) and the inhibition of growth and induction of apoptosis of human breast cancer ( $\mathrm{Li}$ et al., 2009). All the aforementioned bioactivities of jambolan have been at least partly ascribed to its phenolic constituents, mainly to the high content of anthocyanins in this fruit (Aqil et al., 2012; Brito et al., 2007; Faria, Marques, \& Mercadante, 2011; Hassimotto et al., 2005; Rufino et al., 2011; Veigas et al., 2007). Few studies have been focused on the identification of other phytochemical constituents of jambolan, which may also contribute to its various health properties, with only a partial and limited study of diverse phenolics, including some flavonols and flavanonols (Faria et al., 2011; Gordon, Jungfer, da Silva, Maia, \&
Marx, 2011; Reynertson, Yang, Jiang, Basile, \& Kenelly, 2008) and tannins (Aqil et al., 2012; Gordon et al., 2011; Nuengchamnong \& Ingkaninan, 2009; Omar, Li, Yuan, \& Seeram, 2012; Tong, Wang, Waisundara, \& Huang, 2014; Zhang \& Lin, 2009). Furthermore, the contents of vitamin C (Gordon et al., 2011; Rufino et al., 2011) and carotenoids (Faria et al., 2011) in jambolan have also been studied.

Different parts of this fruit have been recognized to possess the aforementioned biological activities (Srivastava \& Chandra, 2013). As far as the authors know, no further studies have been developed to determine the detailed phenolic composition of each one of the two edible parts (the skin and the pulp) of jambolan which are related to the most important characteristics of this fruit as a foodstuff: color,

Table 1

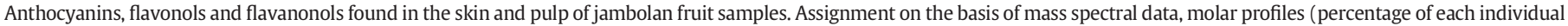
compound within a flavonoid type), and total concentrations ( $\mathrm{mg} / \mathrm{kg}$ FW). Data as mean values \pm standard deviations ( $\mathrm{n}=3$ ).

\begin{tabular}{|c|c|c|c|c|}
\hline Assignment & $\mathrm{MS}^{1}$ & $\mathrm{MS} / \mathrm{MS}^{2}$ & Skin & Pulp \\
\hline \multicolumn{5}{|l|}{ Anthocyanins $^{3}$} \\
\hline$\%$ dp-3,5-O-diglc & 627 & 465,303 & $37.61 \pm 0.09 a$ & $40.39 \pm 0.22 b$ \\
\hline$\%$ cy-3,5-0-diglc & 611 & 449,287 & $3.01 \pm 0.05 \mathrm{a}$ & $3.38 \pm 0.03 b$ \\
\hline$\%$ dp-3-O-glc & 465 & 303 & $1.59 \pm 0.07 \mathrm{~b}$ & $1.14 \pm 0.03 \mathrm{a}$ \\
\hline$\%$ pt.-3,5-O-diglc & 641 & $\mathbf{4 7 9}, 317$ & $33.27 \pm 0.16 b$ & $30.29 \pm 0.10 a$ \\
\hline$\%$ cy-3-O-glc & 449 & 287 & $0.37 \pm 0.02 b$ & $0.19 \pm 0.01 \mathrm{a}$ \\
\hline$\%$ pn-3,5-O-diglc & 625 & 463,301 & $0.69 \pm 0.01 \mathrm{~b}$ & $0.59 \pm 0.02 \mathrm{a}$ \\
\hline$\%$ mv-3,5-0-diglc & 655 & 493,331 & $23.31 \pm 0.08 \mathrm{a}$ & $23.93 \pm 0.16 b$ \\
\hline$\%$ pt.-3-O-glc & 479 & 317 & $\mathrm{NQ}$ & $\mathrm{NQ}$ \\
\hline$\%$ mv-3-O-glc & 493 & 331 & $0.17 \pm 0.01 \mathrm{~b}$ & $0.13 \pm 0.04 \mathrm{a}$ \\
\hline Total anthocyanins ${ }^{4}$ & & & $246.04 \pm 5.46 b$ & $6.43 \pm 1.60 a$ \\
\hline \multicolumn{5}{|l|}{ Flavonols ${ }^{5}$} \\
\hline$\% \mathrm{M}-3-0$-glcU & 493 & 317 & $8.00 \pm 0.03 b$ & $7.53 \pm 0.20 a$ \\
\hline$\% \mathrm{M}-3-0$-gal & 479 & 317 & $1.76 \pm 0.02 \mathrm{a}$ & $2.50 \pm 0.04 b$ \\
\hline$\% \mathrm{M}-3-0$-glc & 479 & 317 & $64.40 \pm 0.15 b$ & $30.31 \pm 0.24 \mathrm{a}$ \\
\hline$\% \mathrm{M}-3-0-\mathrm{rhm}$ & 463 & 317 & $11.92 \pm 0.08 \mathrm{~b}$ & $10.64 \pm 0.13 a$ \\
\hline$\% \mathrm{M}-3-0$-pent & 449 & 317 & $3.21 \pm 0.01 \mathrm{a}$ & $11.55 \pm 0.13 b$ \\
\hline \% L-3-O-gal & 493 & 331 & $1.62 \pm 0.01 \mathrm{a}$ & $5.00 \pm 0.07 b$ \\
\hline$\%$ L-3-O-glc & 493 & 331 & $5.04 \pm 0.03 a$ & $5.82 \pm 0.17 \mathrm{~b}$ \\
\hline$\%$ S-3-O-gal & 507 & 345 & $1.91 \pm 0.01 \mathrm{a}$ & $17.74 \pm 0.14 b$ \\
\hline$\%$ S-3-O-glc & 507 & 345 & $2.13 \pm 0.01 \mathrm{a}$ & $8.92 \pm 0.20 b$ \\
\hline Total flavonols ${ }^{6}$ & & & $70.19 \pm 1.50 \mathrm{~b}$ & $4.31 \pm 0.09 \mathrm{a}$ \\
\hline \multicolumn{5}{|l|}{ Flavanonols ${ }^{7}$} \\
\hline \% DHQ-dihexoside-1 & 627 & 447, 285, 465, 339, 489 & $0.67 \pm 0.25$ & $0.61 \pm 0.61$ \\
\hline \% DHQ-dihexoside-2 & 627 & $\mathbf{4 6 5}, \mathbf{4 4 7}, 285,339,489$ & $5.48 \pm 0.73$ & ND \\
\hline \% DHQ-dihexoside-3 & 627 & $447,285,465,339,489$ & $0.72 \pm 0.31$ & ND \\
\hline \% MDHQ-dihexoside & 641 & 479 & $11.66 \pm 1.87$ & $13.89 \pm 5.20$ \\
\hline \% DHM-dihexoside-1 & 643 & $\mathbf{4 6 3}, 505,283,481,625$ & $6.57 \pm 2.77$ & $10.81 \pm 3.17$ \\
\hline \% DHM-dihexoside-2 & 643 & $463,505,283,481,625$ & $10.66 \pm 5.92$ & $9.49 \pm 3.80$ \\
\hline \% DHM-dihexoside-3 & 643 & $463,505,481,283,625$ & $1.18 \pm 0.79$ & $0.53 \pm 0.50$ \\
\hline$\%$ DHM-dihexoside-4 & 643 & $\mathbf{4 8 1}, 463,319,355,505$ & $8.83 \pm 6.50$ & $17.95 \pm 6.39$ \\
\hline \% DHM-dihexoside-5 & 643 & $\mathbf{4 6 3}, \mathbf{4 8 1}, 355,505,517,283,301,319,625$ & $9.94 \pm 4.25$ & $8.39 \pm 2.64$ \\
\hline \% DHM-dihexoside-6 & 643 & $\mathbf{4 6 3}, \mathbf{4 8 1}, 355,505,517,283,301,319,625$ & $16.38 \pm 4.75$ & $17.37 \pm 5.85$ \\
\hline \% MDHM-dihexoside- 1 & 657 & $477,495,315,283,445,462,300$ & $2.17 \pm 1.22$ & $0.48 \pm 0.84$ \\
\hline$\%$ MDHM-dihexoside-2 & 657 & $477,495,519,297,639$ & $5.71 \pm 3.30$ & $3.68 \pm 0.73$ \\
\hline$\%$ MDHM-dihexoside-3 & 657 & $477,495,519,297,639$ & $0.40 \pm 0.26$ & ND \\
\hline$\%$ MDHM-dihexoside- 4 & 657 & $495,477,315,355,333,519$ & $8.29 \pm 3.59$ & $10.61 \pm 2.86$ \\
\hline$\%$ MDHM-dihexoside-5 & 657 & $495,477,519,355,315,639,333$ & $2.27 \pm 0.87$ & $2.93 \pm 1.59$ \\
\hline$\%$ MDHM-dihexoside- 6 & 657 & $495,477,519,315,333,355,639$ & $1.74 \pm 0.91$ & $3.25 \pm 1.39$ \\
\hline \% DMDHM-dihexoside- 1 & 671 & $491,329,509,297,459$ & $1.11 \pm 0.77$ & ND \\
\hline \% DMDHM-dihexoside-2 & 671 & 509 & $2.31 \pm 0.96$ & ND \\
\hline \% DMDHM-dihexoside-3 & 671 & 509 & $3.25 \pm 2.70$ & ND \\
\hline Total flavanonols $^{8}$ & & & $167.68 \pm 67.56 b$ & $6.37 \pm 1.23 \mathrm{a}$ \\
\hline
\end{tabular}

(a, b) Different low case letters mean significant differences according to ANOVA (Student "t" test; $\alpha<0.05$ ).

NQ identified but not possible to quantitate. ND, not detected.

1 Molecular ions $\left([\mathrm{M}]^{+}\right.$from anthocyanins, as flavylium cations, in positive ionization mode) or deprotonated molecules $\left([\mathrm{M}-\mathrm{H}]^{-}\right.$from flavonols and flavanonols in negative ionization mode) in MS experiments.

2 Fragment ions ( $m / z$ values) in MS/MS experiments obtained from the precursor ions generated in the MS experiments. The most abundant fragment ions in the MS/MS spectra have been highlighted in bold font. The rest of the signals have been ordered by decreasing abundance.

3 Anthocyanins: dp, delphinidin; cy, cyanidin; pt., petunidin, pn, peonidin, mv, malvidin; glc, glucoside.

4 As equivalents of malvidin 3,5-O-diglucoside.

5 Flavonols: M, myricetin; L, laricitrin; S, syringetin; gal, galactoside; glc, glucoside; glcU, glucuronide.

6 As equivalents of myricetin 3-O-glucoside.

7 Flavanonols: DHQ dihydroquercetin; MDHQ methyl-dihydroquercetin; DHM, dihydromyricetin; MDHM, methyl-dihydrolmyricetin; DMDHM, dimethyl-dihydromyricetin.

8 As equivalents of naringin. 
astringency and beneficial properties for health. Therefore, the aim of this work was the comprehensive study of the qualitative and quantitative phenolic composition of Brazilian jambolan by HPLC-DAD-ESI-MS/ MS, namely anthocyanins, flavonols, flavanonols (dihydroflavonols), flavan-3-ol monomers, condensed tannins (proanthocyanidins), and hydrolyzable tannins (gallotannins and ellagitannins), with a special focus on the differences found between the skin and the pulp.

\section{Materials and methods}

\subsection{Chemicals and samples of jambolan fruit}

All solvents were of high performance liquid chromatography (HPLC) quality and all chemicals of analytical grade $(>99 \%)$. Water was of Milli-Q quality. Commercial standards from Phytolab

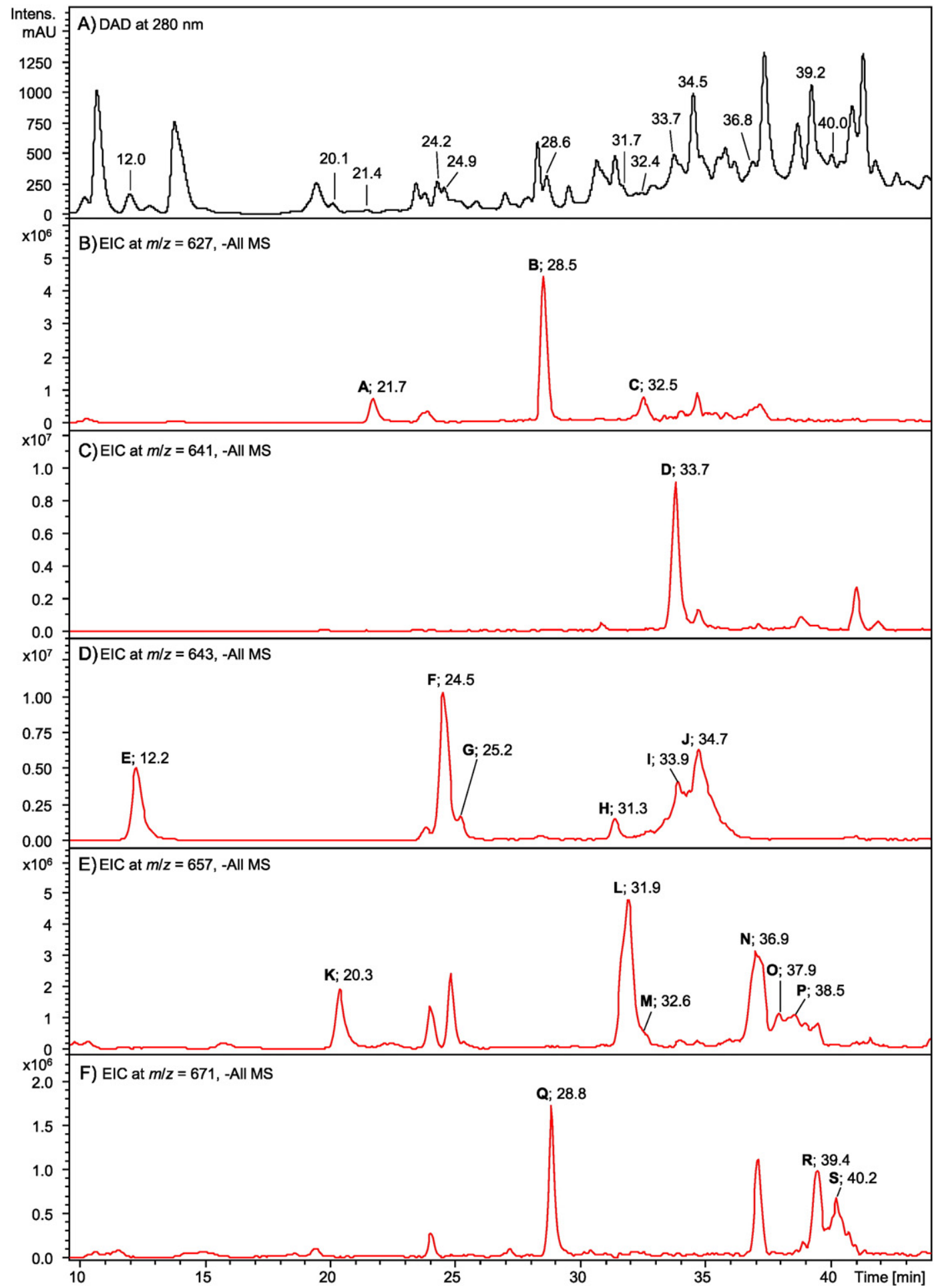

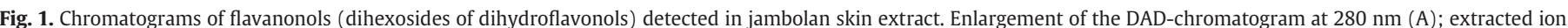

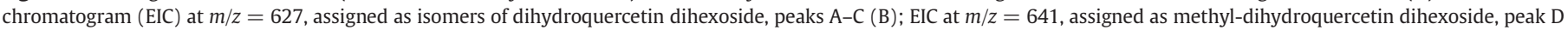

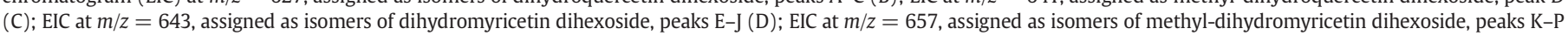
(E); and EIC at $m / z=671$, assigned as isomers of dimethyl-dihydromyricetin dihexoside, peaks Q-S (F). 
(Vestenbergsgreuth, Germany) were used for: malvidin 3-O-glucoside, malvidin 3,5-O-diglucoside, peonidin 3,5-O-diglucoside, (-)epigallocatechin, procyanidin B1 and caftaric acid. Commercial standards from Extrasynthese (Genay, France) were used for: cyanidin 3$\mathrm{O}$-glucoside, cyanidin 3,5-O-diglucoside, the 3-O-glucosides of quercetin, kaempferol, isorhamnetin and syringetin, the 3-O-galactosides of quercetin and syringetin, procyanidin B2, (-)-catechin 3-O-gallate, (-)-epicatechin 3-O-gallate, (-)-epigallocatechin 3-O-gallate, naringin and chlorogenic acid. Pyrogallol, (-)-epicatechin, (-)gallocatechin and ellagic and gallic acids were from Sigma-Aldrich (Tres Cantos, Madrid). (+)-Catechin and (-)-gallocatechin 3-Ogallate were from Fluka (Buchs, Switzerland). The ellagitanins castalagin and vescalagin were provided by ADERA (Pessac, France). Prof. Fernando Zamora (Tarragona, Spain) kindly supplied a sample of procyanidin B4. Other non-commercial flavonol standards (myricetin 3-O-glucoside, quercetin 3-O-glucuronide) were kindly supplied by Dr. Ullrich Engelhardt (Institute of Food Chemistry, Technical University of Braunschweig, Germany) or they were isolated from Petit Verdot grape skins (laricitrin 3-O-glucoside) in a previous study (Castillo-Muñoz et al., 2009). All the available standards were used for the identification of the compounds eluting in the chromatographic peaks. However, the quantitation was carried out by means of the calibration curves of the commercially available standards most representative of each one of the different phenolic compound types: malvidin 3-O-glucoside and malvidin 3,5-O-diglucoside were used, respectively, for all anthocyanidin 3$\mathrm{O}$-glucosides and 3,5-O-diglucosides; myricetin 3-O-glucoside was used for all flavonol 3-O-glycosides; naringin (a flavanone glycoside) was used for all flavanonol glycosides; gallic acid was used for all gallotannins; ellagic acid was used for ellagic acid-pentoside; and castalagin was used for all ellagitannins.

The fruit ( $5 \mathrm{~kg}$ ) was collected at optimum ripeness for harvesting from several trees grown in the city of São José do Rio Preto (northwest of the state of São Paulo, Brazil), which lies at $20^{\circ} 47^{\prime} 08^{\prime \prime} \mathrm{S}$ and $49^{\circ} 21^{\prime}$ $36^{\prime \prime} \mathrm{W}$, and $544 \mathrm{~m}$ above sea level (referred to datum WGS84, World Geodetic System 1984), during the harvest season of 2011. The species was identified by Dr. Regina Sampaio and a voucher specimen (32.214) deposited at the Herbarium SJRP in the IBILCE/UNESP, State of São Paulo,

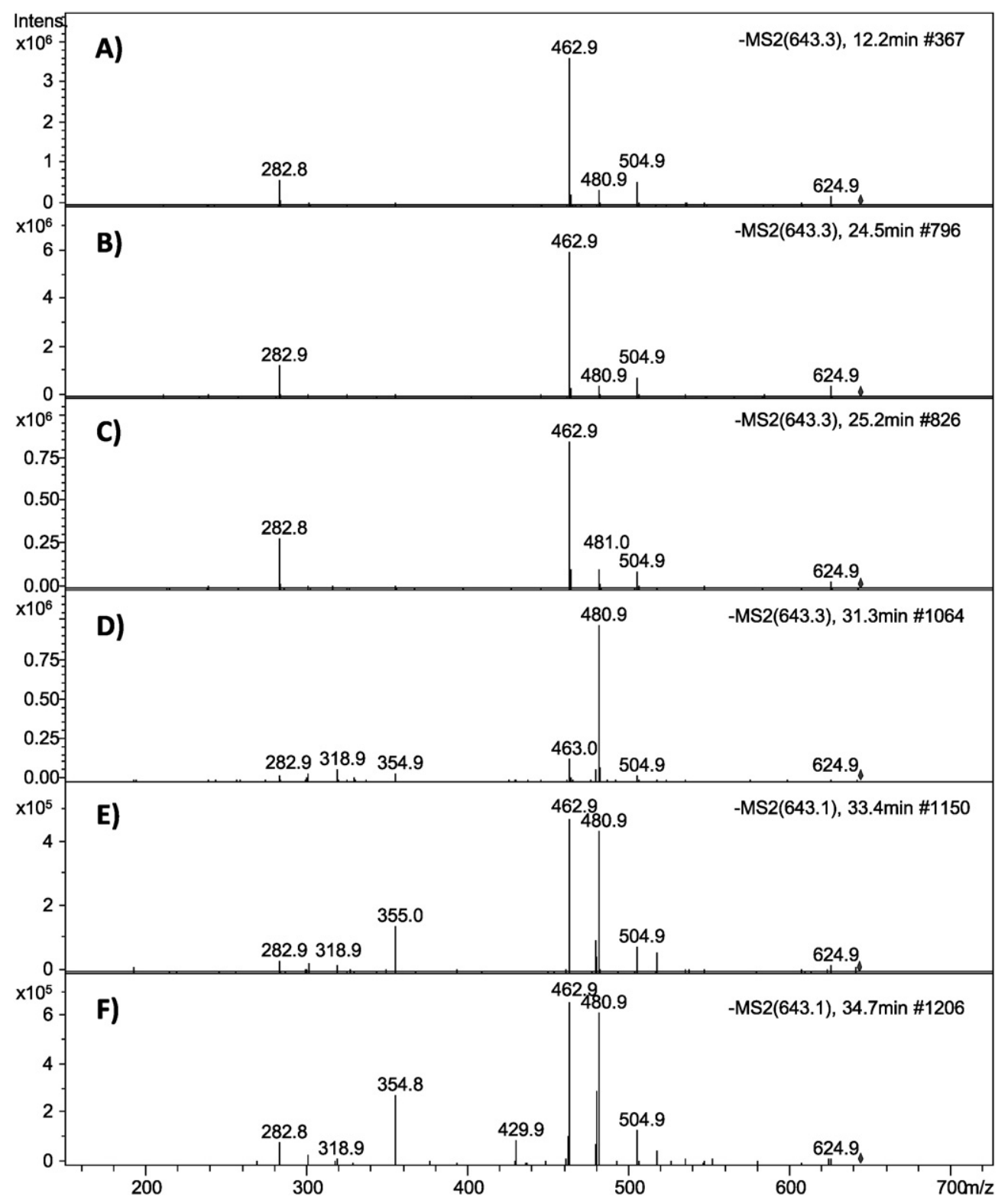

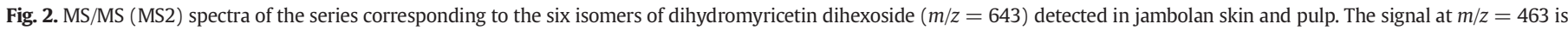

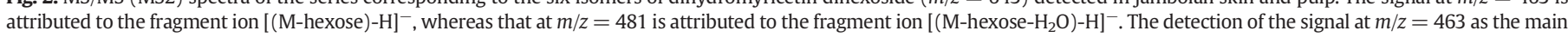
fragment ion is interpreted as an evidence of glycosylation at position $\mathrm{C} 3$ in ring $\mathrm{C}$ of the flavanonol structure. 
Brazil. Once in the lab, the sample was washed with water and gently dried with kitchen paper. The average characteristics of the sampled jambolan fruit were: sugar content (SC) $11.76 \pm 1.37^{\circ}$ Brix; total acidity (TA), $1.86 \pm 0.04 \mathrm{~g} / 100 \mathrm{~g}$, as tartaric acid; $\mathrm{pH}, 3.29 \pm 0.01$; moisture of $87.08 \% \pm 0.24$; and ratio SC/TA of $6.31 \pm 0.68$.

\subsection{Sample preparation}

$200 \mathrm{~g}$ of healthy jambolan fruit was manually and carefully peeled and the resulting skin (25-29\% FW) was immediately frozen at $-80{ }^{\circ} \mathrm{C}$ for $12 \mathrm{~h}$ and then freeze-dried for $24 \mathrm{~h}$ and weighed. The dried skins were homogenized in a porcelain mortar with the aid of a pestle, weighed and afterwards divided into four subsamples, three of which were used for chemical analysis. The subsamples (approximately $2 \mathrm{~g}$ ) were immersed in $50 \mathrm{~mL}$ of a solvent mixture of methanol, water and formic acid (50:48.5:1.5 v/v) and subjected to an ultrasonic bar for $10 \mathrm{~min}$. Samples were then centrifuged at $2500 \mathrm{~g}, 5^{\circ} \mathrm{C}$ for $10 \mathrm{~min}$. A second extraction of the resulting pellets was made using the same volume of the solvent mixture $(50 \mathrm{~mL})$ and the combined supernatants for each sample were maintained under refrigeration $\left(5-7^{\circ} \mathrm{C}\right)$ until the beginning of the analysis. Previous assays of repeated extractions were performed and checked by chromatographic analysis of anthocyanins and flavonols, showing that two consecutive extraction steps were enough for obtaining a quantitative extraction (more than 98\%) of tested compunds. Aliquots of skin extracts were diluted with $0.1 \mathrm{~N}$ $\mathrm{HCl}(1: 10, v / v)$, filtered $(0.20 \mu \mathrm{m}$, polyester membrane, Chromafil PET 20/25, Macherey-Nagel, Düren, Germany) and directly injected onto the HPLC for anthocyanin determination.

The peeled fruit was manually separated into the pulp (54-58\% FW) and the seed (16-21\% FW). The separated pulp was immediately homogenized with $100 \mathrm{~mL}$ of a solvent mixture of methanol, water, and formic acid (70:28.5:1.5, $v / \mathrm{v})$, thus avoiding oxidation, followed by 30 min of agitation in darkness at room temperature. The pulp extract was centrifuged at $10,000 \mathrm{~g}$ at $5{ }^{\circ} \mathrm{C}$ for $20 \mathrm{~min}$. This single extraction step was enough for obtaining a quantitative extraction of the occurring phenolic compounds in jambolan pulp, as confirmed by chromatographic analysis in previous assays. The supernatant was dried in a rotary evaporator $\left(37^{\circ} \mathrm{C}\right)$ and its volume was made up to $100 \mathrm{~mL}$ with water.

To remove the sugars as well as other non-phenolics present in the pulp extract, $3 \mathrm{~mL}$ of extract were diluted with $3 \mathrm{~mL}$ of $0.1 \mathrm{M} \mathrm{HCl}$ and then the prepared sample was passed through C18 SPE-cartridges (Sep-Pak Vac, 3 mL/500 mg 55-105 $\mu \mathrm{m}$; Waters) which had previously been conditioned with $5 \mathrm{~mL}$ of methanol and $5 \mathrm{~mL}$ of water. After washing with $5 \mathrm{~mL}$ of $0.1 \mathrm{M} \mathrm{HCl}$ and $5 \mathrm{~mL}$ of water, the sample was eluted with $3 \times 5 \mathrm{~mL}$ of methanol. The eluate was dried in a rotary evaporator $\left(37^{\circ} \mathrm{C}\right)$, re-dissolved in $3 \mathrm{~mL}$ of $0.1 \mathrm{M} \mathrm{HCl}$, filtered $(0.20 \mu \mathrm{m}$, polyester membrane, Chromafil PET 20/25, Macherey-Nagel, Düren, Germany) and injected directly onto the HPLC system for the determination of anthocyanins.

ECX SPE cartridges ( $40 \mu \mathrm{m}, 500 \mathrm{mg}, 6 \mathrm{~mL}$; Scharlab, Sentmenat, Barcelona, Spain) allowed the isolation of non-anthocyanin phenolic compounds from jambolan skin and pulp extracts (Castillo-Muñoz et al., 2009) and these anthocyanin-free fractions were used to analyze flavonols, flavanonols and hydrolyzable tannins (gallotannins and ellagitannins). Briefly this was the process: $3 \mathrm{~mL}$ of jambolan skin or pulp extracts were diluted with $3 \mathrm{~mL}$ of $0.1 \mathrm{M} \mathrm{HCl}$ and the prepared samples were passed through the SPE cartridges which had previously been conditioned with $5 \mathrm{~mL}$ of methanol and $5 \mathrm{~mL}$ of water. After washing ( $5 \mathrm{~mL}$ of $0.1 \mathrm{M} \mathrm{HCl}$ acid and $5 \mathrm{~mL}$ of water), the anthocyaninfree fractions were eluted with $3 \times 5 \mathrm{~mL}$ of methanol and then dried in a rotary evaporator $\left(37^{\circ} \mathrm{C}\right.$ ) and re-dissolved in $3 \mathrm{~mL}$ of $20 \%$ methanol in water before direct injection onto the HPLC equipment.

Finally, the flavan-3-ols (monomers, B-type dimers, and polymeric proanthocyanidins) were isolated from the jambolan skin and pulp extracts by SPE on C18 cartridges (Sep-pak Plus C18, Waters Corp.,
Milford, MA; cartridges filled with $820 \mathrm{mg}$ of adsorbent). A mixture of $2 \mathrm{~mL}$ of each extract and $12 \mathrm{~mL}$ of water was then passed through the C18 cartridge which had previously been conditioned with methanol $(5 \mathrm{~mL})$ and water $(5 \mathrm{~mL})$. After the cartridge was dried under reduced pressure, methanol $(15 \mathrm{~mL})$ and ethyl acetate $(5 \mathrm{~mL})$ were added in order to recover the adsorbed phenolics. After the solvent was evaporated in a rotary evaporator $\left(35^{\circ} \mathrm{C}\right)$, the residue was dissolved in methanol $(2 \mathrm{~mL})$ and stored at $-18{ }^{\circ} \mathrm{C}$ until needed.

\subsection{Identification and quantitation of non-tannin phenolic compounds by HPLC-DAD-ESI-MS/MS}

Anthocyanins and other non-tannin phenolic compounds from jambolan skin and pulp were separately analyzed using a previously described method (Rebello et al., 2013). For the analysis of anthocyanins, $10 \mu \mathrm{L}$ of diluted extracts was injected, whereas $20 \mu \mathrm{L}$ of anthocyaninfree extract fractions was used for the analysis of non-anthocyanin phenolic compounds different from tannins. The injections were made after filtration $(0.20 \mu \mathrm{m}$, polyester membrane, Chromafil PET 20/25, Machery-Nagel, Düren, Germany) on a reversed-phase column Zorbax Eclipse XDB-C18 $(2.1 \times 150 \mathrm{~mm}$; $3.5 \mu \mathrm{m}$ particle; Agilent, Germany), thermostated at $40{ }^{\circ} \mathrm{C}$., and with a flow rate of $0.19 \mathrm{~mL} / \mathrm{min}$. For identification, an Ion Trap ESI-MS/MS detector was used in both positive (anthocyanins) and negative (flavonols and flavanonols) ion modes, setting the following parameters: dry gas, $\mathrm{N}_{2}, 8 \mathrm{~L} / \mathrm{min}$; drying temperature, $325{ }^{\circ} \mathrm{C}$; nebulizer, $\mathrm{N}_{2}$, $50 \mathrm{psi}$; scan range, $50-1200 \mathrm{~m} / \mathrm{z}$. The ionization and fragmentation parameters were optimized by the direct infusion of the appropriate standard solutions (malvidin 3,5-O-

Table 2

Total concentrations ( $\mathrm{mg} / \mathrm{kg} \mathrm{FW}$, as catechin equivalents) of monomeric flavan-3-ols and their oligomers and polymers (proanthocyanidins) found in the skin and pulp of jambolan fruit samples. Molar profiles (percentage of individual compounds) of monomeric flavan3-ols and monomers involved in proanthocyanidins as terminal or extension units. Data given as mean values \pm standard deviation $(n=3)$. Abbreviations: $\mathrm{mDP}$, mean degree of polymerization; ND, not detected.

\begin{tabular}{|c|c|c|}
\hline & Skin & Pulp \\
\hline \multicolumn{3}{|l|}{ Monomeric flavan-3-ols } \\
\hline$\%$ Catechin & $5.01 \pm 0.55$ & $5.23 \pm 0.84$ \\
\hline \% Epicatechin & $3.25 \pm 0.63$ & $3.47 \pm 0.48$ \\
\hline$\%$ Gallocatechin & $83.97 \pm 1.50$ & $85.82 \pm 0.44$ \\
\hline \% Epigallocatechin & $1.57 \pm 0.29$ & $2.18 \pm 0.27$ \\
\hline \% Epicatechin 3-O-gallate & $0.49 \pm 0.07 \mathrm{~b}$ & $0.11 \pm 0.01 \mathrm{a}$ \\
\hline$\%$ Catechin 3-O-gallate & $0.08 \pm 0.01$ & $0.08 \pm 0.02$ \\
\hline \% Epigallocatechin 3-O-gallate & $5.12 \pm 0.63 b$ & $2.15 \pm 0.40 \mathrm{a}$ \\
\hline \% Gallocatechin 3-O-gallate & $0.50 \pm 0.10 \mathrm{a}$ & $0.97 \pm 0.21 b$ \\
\hline Total monomers & $3.58 \pm 0.89 b$ & $1.27 \pm 0.25 \mathrm{a}$ \\
\hline \multicolumn{3}{|l|}{ Proanthocyanidins } \\
\hline Total proanthocyanidins & $11.92 \pm 3.47$ & $9.03 \pm 1.78$ \\
\hline $\mathrm{mDP}$ & $17.53 \pm 5.93$ & $23.72 \pm 3.70$ \\
\hline \multicolumn{3}{|l|}{ Terminal units } \\
\hline$\%$ catechin & $11.24 \pm 4.42$ & $9.22 \pm 3.99$ \\
\hline \% Epicatechin & ND & ND \\
\hline \% Gallocatechin & $72.20 \pm 9.57$ & $75.20 \pm 6.04$ \\
\hline \% Epigallocatechin & $12.65 \pm 6.18$ & $11.53 \pm 2.07$ \\
\hline \% Epicatechin 3-O-gallate & $1.83 \pm 0.32 b$ & $0.98 \pm 0.34 \mathrm{a}$ \\
\hline$\%$ Catechin 3-O-gallate & $0.64 \pm 0.15 b$ & $0.21 \pm 0.21 \mathrm{a}$ \\
\hline \% Epigallocatechin 3-O-gallate & $1.29 \pm 2.24$ & $2.44 \pm 0.49$ \\
\hline \% Gallocatechin 3-O-gallate & $0.15 \pm 0.26$ & $0.43 \pm 0.45$ \\
\hline \multicolumn{3}{|l|}{ Extension units } \\
\hline$\%$ Catechin & $0.12 \pm 0.05$ & $0.10 \pm 0.02$ \\
\hline \% Epicatechin & $2.12 \pm 1.12$ & $1.21 \pm 0.27$ \\
\hline \% Gallocatechin & $1.66 \pm 0.38$ & $1.13 \pm 0.13$ \\
\hline \% Epigallocatechin & $15.08 \pm 2.29$ & $12.56 \pm 1.20$ \\
\hline \% Epicatechin 3-O-gallate & $0.02 \pm 0.00$ & $0.02 \pm 0.01$ \\
\hline$\%$ Catechin 3-O-gallate & $1.14 \pm 0.05$ & $1.40 \pm 0.28$ \\
\hline \% Epigallocatechin 3-0-gallate & $1.27 \pm 0.17$ & $1.38 \pm 0.05$ \\
\hline \% Gallocatechin 3-O-gallate & $78.59 \pm 3.95$ & $82.21 \pm 0.84$ \\
\hline
\end{tabular}

(a, b) Different letters mean significant differences according to ANOVA (Student's "t" test; $\alpha<0.05$ ). 
diglucoside in positive ionization mode; quercetin 3-O-glucoside and caftaric acid in negative ionization mode). The identification was mainly based on spectroscopic data (UV-vis and MS/MS) obtained from authentic standards or previously reported findings (Castillo-Muñoz et al., 2009; Rebello et al., 2013). For quantitation, DAD-chromatograms were extracted at $520 \mathrm{~nm}$ (anthocyanins) and $360 \mathrm{~nm}$ (flavonols). Analyses were performed in triplicate.

2.4. Identification and quantitation of flavan-3-ol monomers and condensed tannins (proanthocyanidins) using multiple reaction monitoring HPLC-ESI-MS/MS

For the analysis of flavan-3-ol monomers occurring in the skin and pulp of jambolan fruit, $0.25 \mathrm{~mL}$ of the SPE-C18 extract was diluted with $4.75 \mathrm{~mL}$ of water/formic acid $(98.5: 1.5, v / \mathrm{v})$ in a chromatographic vial that was sealed and then injected. The structural information of proanthocyanidins (condensed tannins) was obtained following the method of acid-catalyzed depolymerization induced by pyrogallol (Lago-Vanzela, Da-Silva, Gomes, García-Romero \& Hermosín-Gutiérrez, 2011; Rebello et al., 2013). Thus, $0.50 \mathrm{~mL}$ of pyrogallol reagent solution ( $100 \mathrm{~g} / \mathrm{L}$ of pyrogallol and $20 \mathrm{~g} / \mathrm{L}$ ascorbic acid in methanolic $0.3 \mathrm{~N} \mathrm{HCl}$ ) was added to $0.25 \mathrm{~mL}$ of SPE-C18 extract, and the mixture was then maintained at $30^{\circ} \mathrm{C}$ for $40 \mathrm{~min}$. After the reaction was finalized with the addition of $2.25 \mathrm{~mL}$ of $67 \mathrm{mM}$ sodium acetate and $2 \mathrm{~mL}$ of water, the reaction mixture was then injected.

The HPLC analyses were performed following a previously reported method (Rebello et al., 2103) using an Agilent 1200 series system equipped with a diode array detector (DAD; Agilent, Germany) and coupled to an AB Sciex 3200 Q TRAP (Applied Biosystems) electrospray ionization mass spectrometry system (ESI-MS/MS). The chromatographic system was managed by the Agilent Chem Station (version
B.01.03) data-processing station. The mass spectral data was processed with the Analyst MSD software (Applied Biosystems, version 1.5). The samples (before and after the acid-catalyzed depolymerization reaction) were injected $(10 \mu \mathrm{L})$ onto a reversed-phase column Agilent Eclipse XDB-C18 (2.1 $\times 150 \mathrm{~mm}$; $3.5 \mu \mathrm{m}$ particle; Agilent, Germany), thermostated at $16{ }^{\circ} \mathrm{C}$ and with a flow rate of $0.1 \mathrm{~mL} / \mathrm{min}$. Two MS scan types were used: enhanced MS (EMS) for compound identification, and multiple reaction monitoring (MRM) for quantitation, using the previously established MS conditions for both scan types (Rebello et al., 2013).

For the identification and quantitation of diverse flavan-3-ols, standards of the monomers $(+)$-catechin, $(-)$-epicatechin, $(-)$-epigallocatechin, (-)-gallocatechin, and (-)-epicatechin 3-0-gallate and the dimers procyanidins B1, B2 and B4 were used. The total content of polymeric proanthocyanidins was quantitated as equivalents of $(+)$ catechin and their structural features were characterized (molar percentage of each one of the extension and terminal subunits; and mean degree of polymerization, $\mathrm{mDP}$ ).

\subsection{Identification and quantitation of hydrolyzable tannins (gallotannins and ellagitannins) by HPLC-DAD-ESI-MS/MS}

The anthocyanin-free fractions obtained from the extracts of jambolan skin and pulp were directly injected $(20 \mu \mathrm{L})$ onto the same chromatographic equipment used for the analysis of non-tannin phenolic compounds (Section 2.3) with the same chromatographic conditions (chromatographic column, column temperature, solvent system and gradient). For identification, an Ion Trap ESI-MS/MS detector was used in negative ion mode, setting the following parameters: dry gas, $\mathrm{N}_{2}$, $8 \mathrm{~L} / \mathrm{min}$; drying temperature, $325^{\circ} \mathrm{C}$; nebulizer, $\mathrm{N}_{2}, 50 \mathrm{psi}$; scan range, $50-1200 \mathrm{~m} / \mathrm{z}$. The ionization and fragmentation parameters were

Table 3

Chromatographic (retention times, min) and spectral (UV, MS and MS/MS) data and suggested assignment of gallotannins and ellagitannins found in jambolan fruit.

\begin{tabular}{|c|c|c|c|c|c|}
\hline Peak $^{\mathrm{a}}$ & $R_{\mathrm{t}}$ & $U V^{\mathrm{b}}$ & $\mathrm{MS}^{\mathrm{c}}$ & $\mathrm{MS} / \mathrm{MS}^{\mathrm{c}}$ & Assignment $^{\mathrm{d}}$ \\
\hline 1 & 10.9 & 229,278 & 663 & 331 (MS3: 169) & G-glc \\
\hline GA & 13.5 & 228,271 & 169 & ND & Gallic acide \\
\hline 2 & 35.6 & 230,276 & 635 & $617,483, \mathbf{4 6 5}, 313$ & 3G-glc-1 \\
\hline 3 & 37.5 & 231,277 & 483 & $423,331,313,271,211,169$ & 2G-glc \\
\hline 4 & 37.7 & 231,277 & 635 & $617,483,465,423,295,313$ & $3 G-$ glc-2 \\
\hline 5 & 40.2 & 232, 277 & 635 & $617, \mathbf{4 8 3}, 465,423,313$ & $3 G$-glc-3 \\
\hline 6 & 40.9 & 232,277 & 787 & $\mathbf{6 3 5}, 617,465$ & 4G-glc-1 \\
\hline 7 & 41.5 & 231,278 & 635 & (617), 483, (465), (423), (313) & $3 G-$ glc- 4 \\
\hline 8 & 44.5 & 230,278 & 787 & $635, \mathbf{6 1 7}, 573,465$ & $4 G-$ glc-2 \\
\hline 9 & 45.8 & 231,278 & 939 & 787 & 5G-glc-1 \\
\hline 10 & 46.8 & 231,277 & 939 & 787 & $5 G-$ glc- 2 \\
\hline 11 & 47.5 & 231,279 & 939 & 787, 769, 617 & $5 G-$ glc-3 \\
\hline 12 & 49.0 & ND & 1091 & 939, 787 & $6 G$-glc-1 \\
\hline 13 & 49.9 & 230,276 & 1091 & 939, 787 & $6 G$-glc-2 \\
\hline $\mathrm{a}$ & 13.0 & 235,270 sh & 933 & $\mathbf{9 1 5}, 897,889,871,853,631,613,569,425$ & Vescalagin $^{e}$ \\
\hline b & 19.0 & 235,270 sh & 933 & $\mathbf{9 1 5}, \mathbf{8 9 7}, 889,871,853, \mathbf{6 3 1}, 613,587,569,467,425$ & Castalagin $^{\mathrm{e}}$ \\
\hline c & 19.8 & ND & 783 & $763, \mathbf{4 8 1}, 421, \mathbf{3 0 1}, 275,229$ & 2HHDP-glc-1 \\
\hline d & 26.1 & 238,270 sh & 783 & $763, \mathbf{4 8 1}, 421, \mathbf{3 0 1}, 275,229$ & 2HHDP-glc-2 \\
\hline $\mathrm{e}$ & 28.9 & 233,279 & 951 & 907, 783 & Trisgalloyl-HHDP-glc-1 \\
\hline $\mathrm{f}$ & 30.1 & ND & 785 & $765, \mathbf{6 3 3}, 615, \mathbf{4 8 3}, 419, \mathbf{3 0 1}, 275,249$ & 2G-HHDP-glc-1 \\
\hline g & 30.7 & ND & 951 & 907,783 & Trisgalloyl-HHDP-glc-2 \\
\hline $\mathrm{h}$ & 33.6 & ND & 935 & $\mathbf{9 1 7}, 873,853,783,659, \mathbf{6 3 3}, 615,589,571,383,301$ & G-2HHDP-glc-1 \\
\hline i & 34.7 & 236, 278 & 643 & $625,517,505, \mathbf{4 8 1}, \mathbf{4 6 3}, 429,355,301,283$ & Unknown ellagitannin \\
\hline $\mathrm{j}$ & 36.5 & 231,277 & 785 & $765, \mathbf{6 3 3}, 615, \mathbf{4 8 3}, 419, \mathbf{3 0 1}, 275,249$ & 2G-HHDP-glc-2 \\
\hline $\mathrm{k}$ & 39.5 & 237,277 & 935 & 633,301 & G-2HHDP-glc-2 \\
\hline 1 & 42.1 & 230, 278 & 937 & $893,785, \mathbf{7 6 7}, \mathbf{7 4 1}, 635,483,465,419,301$ & 3G-HHDP-glc \\
\hline $\mathrm{m}$ & 42.9 & ND & 785 & $765, \mathbf{6 3 3}, 615, \mathbf{4 8 3}, 419, \mathbf{3 0 1}, 249$ & 2G-HHDP-glc-3 \\
\hline $\mathrm{n}$ & 52.8 & 253, 300sh, 350sh, 361 & 433 & 301 & Ellagic acid-pentoside \\
\hline 0 & 54.0 & 254, 300sh, 350sh, 368 & 301 & 301 & Ellagic acide \\
\hline
\end{tabular}

a Peak numbers and letters as in Fig. 2.

b Predominant UV absorbance band (nm) in bold.

c Deprotonated molecules $\left([\mathrm{M}-\mathrm{H}]^{-}\right)$in MS experiments and fragment ions $(\mathrm{m} / \mathrm{z}$ ) in MS/MS experiments. Most intense signal/s in MS/MS spectra is/are highlighted in bold (only one signal is more intense than the rest) and bold-italic (two or more signals are more intense than the rest, the most intense being highlighted in bold and the others in bold-italic).

d (n)G, number (n) of galloyl substituents; glc, glucose; (n)HHDP, number ( $\mathrm{n}$ ) of hexahydroxydiphenoyl substituents; compounds assigned with the same name but different end numbers are isomers.

e In some cases, the compound assignment was confirmed by comparison with an available standard. 
optimized by direct infusion of a solution of castalagin in a mixture of solvents A and B 50\% each. The identification was mainly based on spectroscopic data (UV-vis and MS/MS) obtained from authentic standards or previously reported findings (Boulekbache-Makhlouf, Meudec, Chibane, \& Mazauric, 2010; Gordon et al., 2011; Meyers, Swiecki, \& Mitchell, 2006; Nuengchamnong \& Ingkaninan, 2009;
Santos, Freire, Domingues, Silvestre, \& Neto, 2011; Tong et al., 2014; Zhu et al., 2009).

The analysis of flavanonols (dihydroflavonols) was also done in the same chromatographic run used for the identification and quantitation of hydrolyzable tannins, using the signal obtained at $280 \mathrm{~nm}$ and naringin as an external standard.

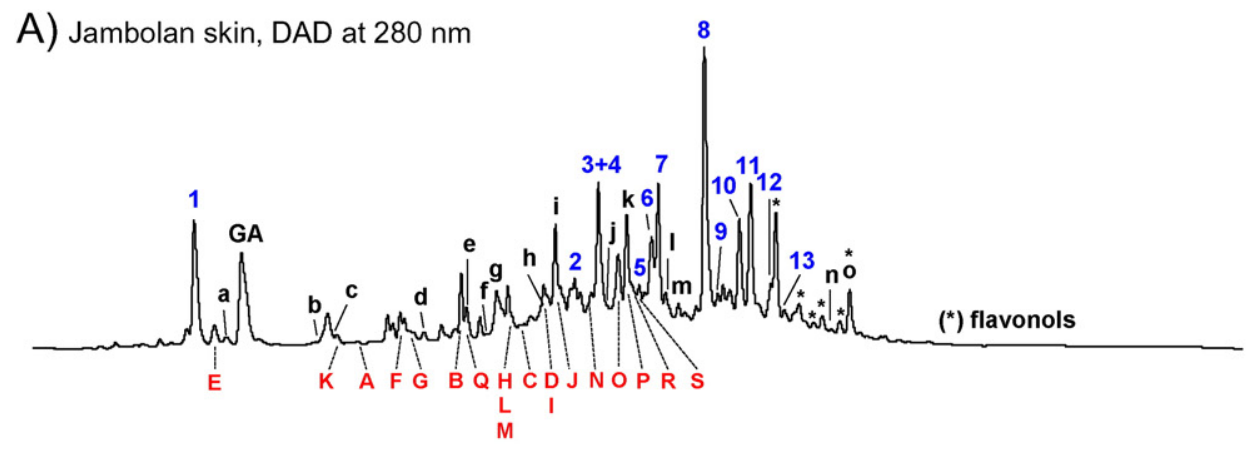

B) Jambolan skin, EIC of ellagitannins

EIC 663 (331) -All MS

EIC 483 -All MS

EIC 635 -All MS

EIC 787 -All MS

EIC 939 -All MS

EIC 1091 -All MS

C) Jambolan skin, EIC of gallotannins

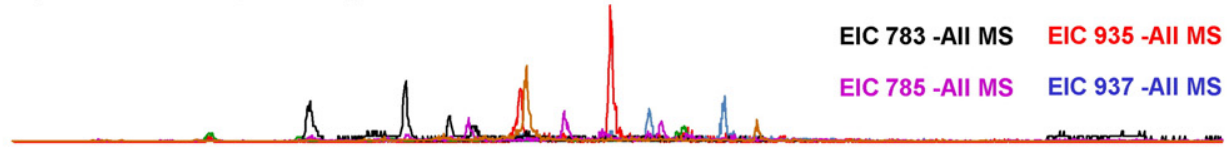

D) Jambolan pulp, DAD at $280 \mathrm{~nm}$

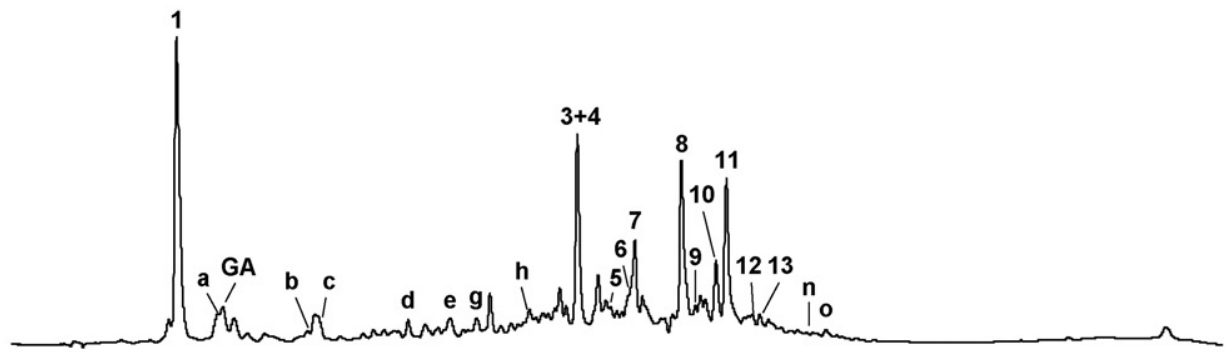

\section{E) Jambolan pulp, EIC of gallotannins}

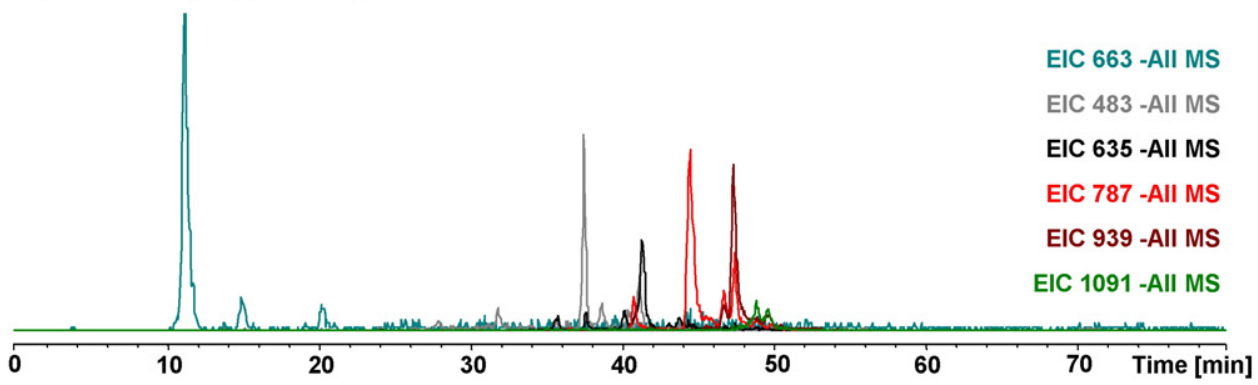

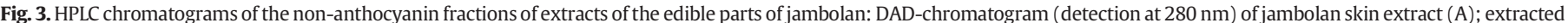

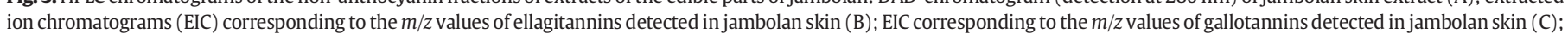

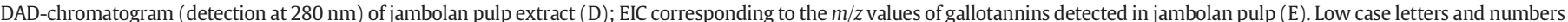

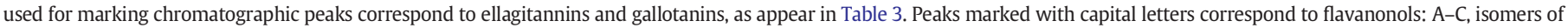

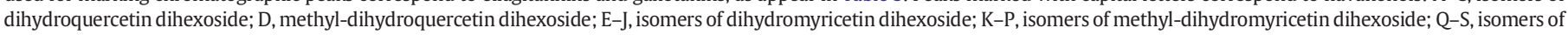
dimethyl-dihydromyricetin dihexoside. 
2.6. Estimation of total hydrolyzable tannins (gallotannins and ellagitannins) by HPLC-DAD-ESI-MS/MS after acidic hydrolysis

The total content of gallotannins and ellagitannins was estimated after acidic hydrolysis, following a modification of a previously reported method (Peng, Scalbert, \& Monties, 1991). Methanol $(2100 \mu \mathrm{L}), 37 \% \mathrm{HCl}$ $(600 \mu \mathrm{L})$ and a sample of $20 \%$ methanolic solution of an anthocyaninfree fraction of the extracts of jambolan skin and pulp $(300 \mu \mathrm{L})$ were mixed in a sealed vial $(10 \mathrm{~mL})$. After heating in boiling water for $2 \mathrm{~h}$, the vial was cooled (mixture of water and ice) and then $3 \mathrm{~mL}$ of water was added to the mixture. Then the mixture was homogenized, filtered ( $0.20 \mu \mathrm{m}$, polyester membrane, Chromafil PET 20/25, Machery-Nagel, Düren, Germany) and analyzed following the same chromatographic method applied to hydrolyzable tannins (Section 2.5). The identification was based on spectroscopic data (UV-vis and MS/MS) obtained from authentic standards or previously reported findings (Santos et al., 2011). The quantitation was performed at $280 \mathrm{~nm}$ using the calibration curves obtained for gallic and ellagic acids.

\subsection{Statistical analysis}

Phenolic composition data corresponding to skin and pulp samples of jambolan fruit were subjected to ANOVA (Student " $\mathrm{t}$ " test and $\mathrm{p}<0.05$; SPSS statistical software pack). All analyses were made in triplicate and the results were given as mean values with their corresponding standard deviations.

\section{Results and discussion}

\subsection{Non-tannin phenolic compounds}

Anthocyanins are important phenolic compounds found in jambolan fruit (Table 1). They are mainly located in the fruit skin, but lower amounts of anthocyanins were also detected in the pulp. Jambolan usually presents a colorless pulp and the detection of anthocyanins in this fruit part could be due to migration from the skins and/or the colored seed, very likely during the sample preparation or as a consequence of fruit over-ripening. The content of anthocyanins in the pulp of jambolan was remarkably lower $(69.43 \mathrm{mg} / \mathrm{kg} \mathrm{FW}$, as malvidin 3,50 -diglucoside) than in the skins ( $246.04 \mathrm{mg} / \mathrm{kg} \mathrm{FW})$. The total anthocyanin content, considering skin and pulp together, was $315.47 \mathrm{mg} / \mathrm{kg} \mathrm{FW}$ (as malvidin 3,5-O-diglucoside), which corresponded to a calculated value of $270 \mathrm{mg}$, as cyanidin 3-O-glucoside, per $100 \mathrm{~g}$ of dry weight (DW) of the edible parts of the fruit, which compared better to literature data. This anthocyanin content was lower than that reported by Brito

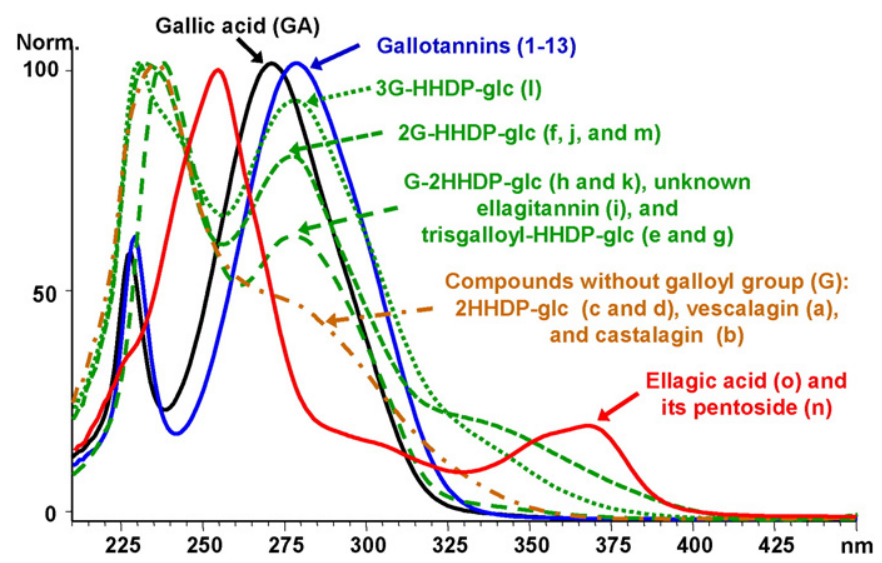

Fig. 4. On-line DAD UV-vis spectra of the hydrolyzable tannins found in jambolan, together with those of some of their constituent units, namely gallic acid and ellagic acid (and its pentoside). Numbers and low case letters correspond to the same peaks shown in Table 3. et al. (2007) for Brazilian jambolan whole fruit (771 mg/100 g DW of fruit, as cyanidin 3-O-glucoside, obtained from HPLC chromatograms at $520 \mathrm{~nm}$ ). In contrast, our results were higher than those reported by Veigas et al. (2007) for Indian jambolan skin, $230 \mathrm{mg} / 100 \mathrm{~g}$ DW of skin, as cyanidin 3-O-glucoside, measured by the $\mathrm{pH}$ differential spectrophotometric method, and by Faria et al. (2011) for Brazilian jambolan edible parts (homogenized skin and pulp) of fruit (211 and $158 \mathrm{mg} / 100 \mathrm{~g}$ DW of the fruit and a functional extract respectively, as cyanidin 3-0-glucoside, measured by the $\mathrm{pH}$ differential spectrophotometric method). These current results confirmed that jambolan is an anthocyanin-rich fruit and strongly suggest that its undervalued use as food must be revised because it is an excellent source of bioactive anthocyanins.

The reported anthocyanin profile of jambolan (Brito et al., 2007; Li et al., 2009; Veigas et al., 2007; Faria et al., 2011; Gordon et al., 2011) is dominated by B-ring trisubstituted anthocyanidins, namely the 3,50 -diglucosides of delphinidin (23-45\%), petunidin (32-25\%) and malvidin (15-38\%) in good agreement with our results (Table 1). The 3,5-O-diglucosides of B-ring disubstituted anthocyanidins, namely cyanidin and peonidin, together with the 3-O-glucosides of delphinidin, cyanidin, petunidin and malvidin, were also found as minor anthocyanins (molar percentages below 4\%), in agreement with previously reported data (Brito et al., 2007; Li et al., 2009; Faria et al., 2011). The anthocyanin profiles found in the skin and the pulp of the jambolan fruit were rather similar although some significant differences could be observed, mainly with regard to the proportions of two of the more important anthocyanins, the 3,5-O-diglucosides of delphinidin (slightly higher proportion found in the pulp) and petunidin (slightly higher proportion found in the skin).

Obtaining anthocyanin-free fractions of jambolan skin and pulp extracts facilitated the analysis of non-anthocyanin phenolic compounds. Thus, a total of nine flavonol glycosides were tentatively identified (Table 1) and no peaks corresponding to free aglycones were observed. All the latter compounds showed a flavonoid B-ring trisubstituted pattern that was assigned mainly on the basis of the unique fragment ion observed in the MS/MS spectra obtained in negative ionization mode: myricetin, $m / z=317$; laricitrin, $m / z=331$; and syringetin, $m / z=345$ (Castillo-Muñoz et al., 2009). There is very little data in the literature on the flavonol composition of the edible parts of jambolan. On the one hand, the occurrence of quercetin and some of their glycosides has been reported based only on the matching of retention times of the corresponding standards (Reynertson et al., 2008). On the other hand, more recent studies have identified flavonol derivatives with only one B-ring trisubstituted pattern on the basis of MS data. In one case, only myricetin derivatives were found (Faria et al., 2011) whereas in the other case five myricetin glycosides, together with seven methylmyricetin (possibly laricitrin), three dimethylmyricetin (possibly syringetin) glycosides and free myricetin were found (Gordon et al., 2011). The latter work also suggested that the so-called methylmyricetin structure should be assigned as $4^{\prime}-0$-methylmyricetin instead of laricitrin (3'-Omethylmyricetin), on the basis that the occurrence of this compound was unambiguously assigned by NMR spectroscopy in jambolan leaves (Mahmoud, Marzouk, Moharram, El-Gindi, \& Hassan, 2001). However, the assignment made in our work was also supported by the matching of chromatographic and spectral data of some of the suggested flavonol glycosides with those of available standards, namely the 3-O-glucosides of myricetin, laricitrin and syringetin, and the 3-O-galactoside of syringetin, as well as the coincidence of chromatographic elution profiles with those corresponding to the well-known grape flavonols (Castillo-Muñoz et al., 2009).

As observed for anthocyanins, flavonols were mainly present in the skin of jambolan and their total content in the fruit was $74.50 \mathrm{mg} / \mathrm{kg}$ FW (as myricetin 3-O-glucoside). In contrast to that found for anthocyanin profiles, the flavonol profiles were clearly and significantly different according to the fruit part, with a clear predominance of 
myricetin 3-0-glucoside in the skin (64.40\%) that decreased in percentage in the case of the pulp (30.31\%), together with a remarkable increase in the contribution of syringetin 3-O-galactoside (from 1.91\% in the skin to $17.74 \%$ in the pulp). As far as the authors know, the only reported data on the flavonol composition of the edible parts of jambolan indicates the occurrence of 0.01 and $0.13 \mathrm{mg} / \mathrm{g}$ DW of quercetin and rutin (the 3-0-rutinoside of quercetin) respectively (Reynertson et al., 2008) based on the identification of individual compounds by their chromatographic mobility. The latter data about flavonol contents of jambolan fruit were rather low in comparison to those found in our study, which were calculated on a basis of $\mathrm{mg} / \mathrm{g}$ DW as being $0.60 \mathrm{mg} / \mathrm{g} \mathrm{DW}$ (as quercetin) or $1.29 \mathrm{mg} / \mathrm{g} \mathrm{DW}$ (as rutin), although no flavonols based on quercetin were identified.

Flavanonols, also named dihydroflavonols, have been noted to occur in the edible parts of jambolan as dihexosides (Faria et al., 2011; Gordon et al., 2011). The presence of such compounds was investigated in the same chromatographic runs used for the analysis of hydrolyzable tannins by means of the ion extracted chromatograms (EIC) at the $\mathrm{m} / \mathrm{z}$ values of the expected deprotonated molecules (Fig. 1) and the evaluation of the MS/MS spectrum of every detected peak. A total of nineteen peaks attributable to flavanonols were detected (peaks marked with capital letters, A to S): three of them in the EIC at $\mathrm{m} / \mathrm{z}=627$ (dihexosides of dihydroquercetin; peaks A to C, with retention times of 21.7, 28.5 and 32.5 min respectively), one of them in the EIC at $m / z=641$ (dihexoside of methyl-dihydroquercetin; peak $D$, with retention time of $33.7 \mathrm{~min}$ ), six of them in the EIC at $\mathrm{m} / z=643$ (dihexosides of dihydromyricetin; peaks $\mathrm{E}$ to J, with retention times of $12.2,24.5,25.2,31.3,33.9$ and 34.7 min respectively), six more in the EIC at $m / z=657$ (dihexosides of methyl-dihydromyricetin; peaks $\mathrm{K}$ to $\mathrm{P}$, with retention times of $20.3,31.9,32.6,36.9,37.9$ and $38.5 \mathrm{~min}$ respectively) and, finally, three more at $m / z=671$ (dihexoside of dimethyl-dihydromyricetin; peaks $Q$ to $S$, with retention times of 28.8, 39.3 and $40.2 \mathrm{~min}$ respectively). The occurrence of dihydroquercetin 3,7-di-O-glucoside in jambolan has been suggested (Faria et al., 2011) but we have now found up to three possible isomers of dihydroquercetin dihexosides (peaks A to $\mathrm{C}$ ). In addition, we are now reporting for the first time on the occurrence in jambolan of a flavanonol with a likely structure of methyl-dihydroquercetin dihexoside (peak D). Moreover, the occurrence in jambolan of several flavanonols with structures based on dihydromyricetin that has a B-ring trisubstituted pattern have been already reported: in one case, the 3,7-di-O-glucosides of dihydromyricetin, methyl-dihydromyricetin and dimethyl-dihydromyricetin have been
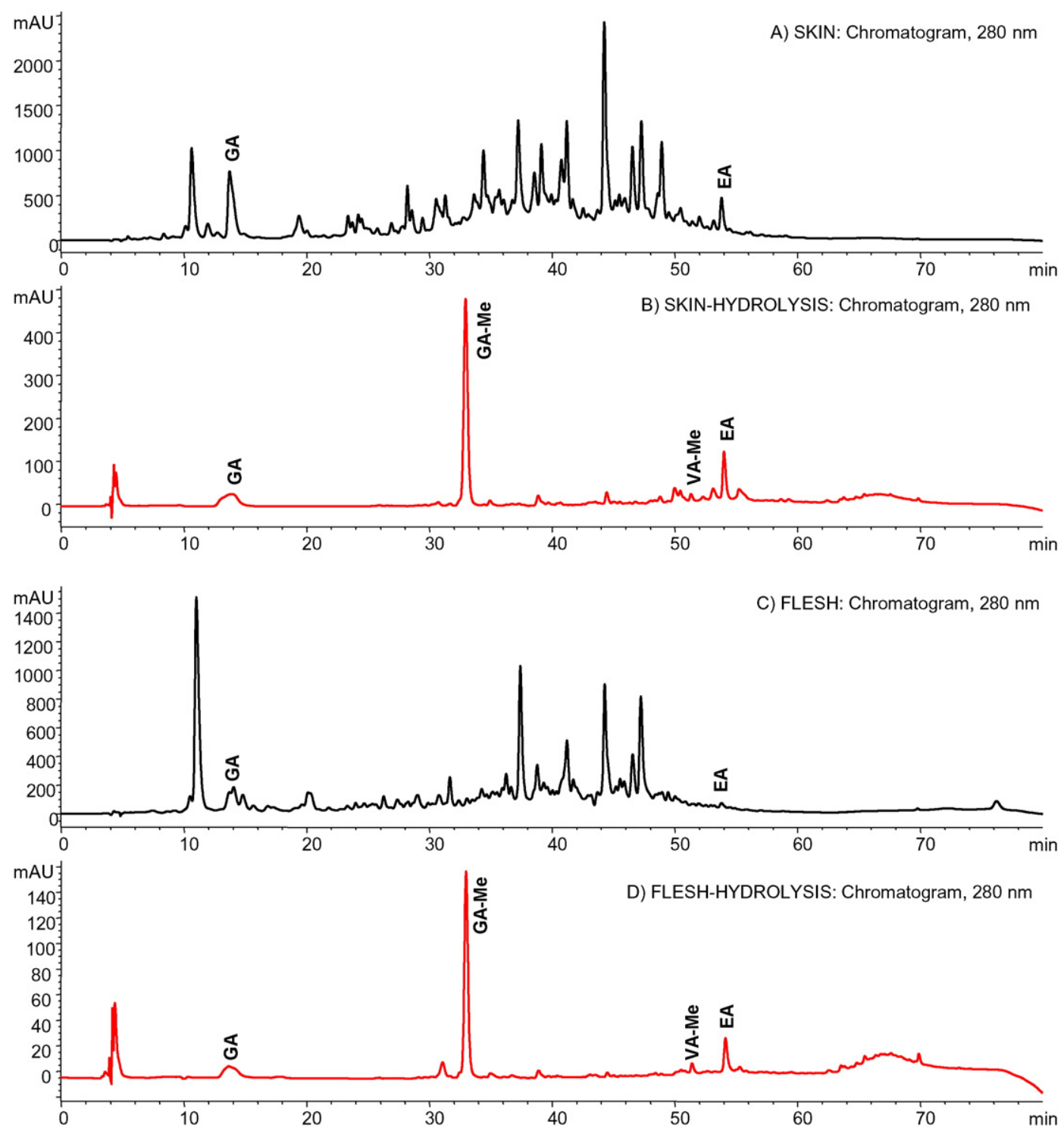

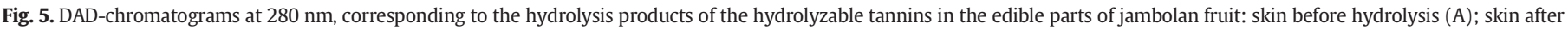

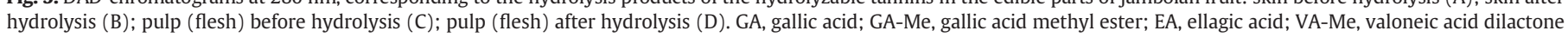
methyl ester. 
suggested (Faria et al., 2011); in another case, the suggested structures were one dihydromyricetin dihexoside, two isomers of methyl-dihydromyricetin dihexoside and two isomers of dimethyldihydromyricetin dihexoside (Gordon et al., 2011). We are now reporting for the first time on the occurrence in jambolan of up to 15 flavanonol dihexosides that could be assigned as derivatives of B-ring trisubstituted aglycones based on dihydromyricetin, instead of the only 5 similar structures previously described. The latter dihydromyricetinbased flavanonol dihexosides accounted for most of the flavonols found in jambolan: $81.47 \%$ in the skin and $85.50 \%$ in the pulp.

The number of possible flavanonols in jambolan, all of them showing MS and MS/MS spectra in agreement with previous reported data, is very high and many of them seem to constitute series of isomers. Within a set of isomers, the fragmentation patterns observed in their respective MS/MS spectra showed several signals which partially matched with those previously reported (Faria et al., 2011; Gordon et al., 2011) and can be classified into two types (Fig. 2 and Table 1). On the one hand, the main signal in the MS/MS spectra of one type of isomers corresponds to the neutral loss of $180 \mathrm{u}$, that is, the loss of a molecule of hexose (Fig. 2A, B and C). On the other hand, the main signal in the MS/MS spectra of the other type of isomers corresponds to the neutral loss of $162 \mathrm{u}$, which is attributable to a neutral loss of dehydrated hexose (Fig. 2D, E and F). The loss of an entire molecule of hexose is only possible if the hexose is linked to position $\mathrm{C} 3$ of the C-ring of a

\section{Table 4}

Individual and total concentrations ( $\mathrm{mg} / \mathrm{kg} \mathrm{FW}$ ) of free gallic acid, free ellagic acid and its pentoside (both as ellagic acid equivalents), gallotannins (as gallic acid equivalents), and ellagitannins (as castalagin equivalents) found in the skin and pulp of jambolan samples. Data as mean values \pm standard deviation $(n=3)$.

\begin{tabular}{|c|c|c|}
\hline Compound* & Skin & Pulp \\
\hline Free gallic acid & $24.08 \pm 19.80$ & $8.20 \pm 0.02$ \\
\hline Free ellagic acid & $14.04 \pm 3.45 b$ & $2.43 \pm 0.60 \mathrm{a}$ \\
\hline Ellagic acid-pentoside & $0.93 \pm 0.10$ & $0.76 \pm 0.15$ \\
\hline \multicolumn{3}{|l|}{ Gallotannins } \\
\hline G-glc & $42.33 \pm 7.12$ & $55.00 \pm 14.36$ \\
\hline 3G-glc-1 & $7.79 \pm 2.22$ & ND \\
\hline $2 \mathrm{G}$-glc $+3 \mathrm{G}$-glc- 2 & $42.50 \pm 7.89$ & $29.42 \pm 1.99$ \\
\hline $3 G-$ glc-3 & $5.20 \pm 2.87$ & $3.58 \pm 2.59$ \\
\hline $3 G-$ glc- 4 & $38.65 \pm 8.08 b$ & $16.56 \pm 0.13 a$ \\
\hline 4G-glc-1 & $25.78 \pm 6.26 b$ & $4.99 \pm 0.87 \mathrm{a}$ \\
\hline $4 G$-glc- 2 & $80.80 \pm 12.03 b$ & $24.51 \pm 0.61 \mathrm{a}$ \\
\hline $5 G-$ glc-1 & $8.28 \pm 2.62$ & $3.38 \pm 0.93$ \\
\hline $5 G-$ glc- 2 & $30.45 \pm 5.76 b$ & $12.04 \pm 1.32 \mathrm{a}$ \\
\hline $5 G$-glc-3 & $38.72 \pm 8.12$ & $25.23 \pm 0.47$ \\
\hline 6G-glc-1 & $12.33 \pm 3.85 b$ & $1.86 \pm 0.08 \mathrm{a}$ \\
\hline $6 G-$ glc-2 & $4.56 \pm 1.76$ & $1.82 \pm 0.15$ \\
\hline Total gallotannins & $337.38 \pm 59.98 b$ & $178.39 \pm 10.67 \mathrm{a}$ \\
\hline \multicolumn{3}{|l|}{ Ellagitannins } \\
\hline Vescalagin & $10.03 \pm 2.38 \mathrm{a}$ & $26.57 \pm 6.37 b$ \\
\hline Castalagin & $6.66 \pm 1.05$ & $8.25 \pm 2.15$ \\
\hline 2HHDP-glc-1 & $13.12 \pm 2.03$ & $15.27 \pm 0.54$ \\
\hline 2HHDP-glc-2 & $7.66 \pm 1.46$ & $10.40 \pm 1.91$ \\
\hline G-2HHDP-glc-1 & $0.08 \pm 0.00 \mathrm{a}$ & $19.94 \pm 1.15 b$ \\
\hline G-2HHDP-glc-2 & $88.72 \pm 17.69$ & ND \\
\hline 2G-HHDP-glc-1 & $2.69 \pm 1.34$ & ND \\
\hline 2G-HHDP-glc-2 & NQ & ND \\
\hline 2G-HHDP-glc-3 & $10.02 \pm 1.74$ & ND \\
\hline 3G-HHDP-glc & $16.74 \pm 3.68$ & ND \\
\hline Trisgalloyl-HHDP-glc-1 & $23.79 \pm 6.67$ & $14.01 \pm 1.88$ \\
\hline Trisgalloyl-HHDP-glc-2 & $30.45 \pm 6.59 b$ & $11.04 \pm 2.15 \mathrm{a}$ \\
\hline Unknown ellagitannin & $75.97 \pm 20.24$ & ND \\
\hline Total ellagitannins & $285.92 \pm 53.42 b$ & $105.48 \pm 13.85 a$ \\
\hline
\end{tabular}

*(n)G, number ( $\mathrm{n}$ ) of galloyl (G) substituents; glc, glucose; (n)HHDP, number (n) of hexahydroxydiphenoyl substituents; compounds assigned with the same name but different end numbers are isomers.

(a, b) Different letters mean significant differences according to ANOVA (Student's " $t$ " test; $\alpha<0.05)$.

ND, not detected; NQ detected but not possible to quantitate. flavanonol, resulting in the formation of a double bond between positions $\mathrm{C} 2$ and $\mathrm{C} 3$ in the $\mathrm{C}$-ring. In contrast, if the hexose is bonded to one of the hydroxyl groups of rings $\mathrm{A}$ and $\mathrm{B}$ of the flavanonol the loss of hexose is only possible through its dehydration. Therefore, the detection of the fragment $[\mathrm{M} \text {-hexose-H] }]^{-}$as the main signal in the MS/MS spectra could serve to suggest that one of the hexoses is linked to the hydroxyl group of position $\mathrm{C} 3$ in ring $\mathrm{C}$ of the flavanonol. The other glycosylation position could be the hydroxyl groups linked to positions C5 and C7 of ring A and at least one of the hydroxyl groups of ring B. Therefore, three of the six isomers derived from dihydromyricetin and methyl-dyhydromyricetin and at least one derived from dimethyldihydromyricetin very likely presented a hexose linked to position C3 of ring $C$.

As far as the authors know, there is no data in the literature about the amounts of flavanonols found in jambolan fruit. Because many of these compounds appeared as overlapped chromatographic peaks, an accurate quantitation using the DAD-chromatograms could not be achieved. However, an estimation of the content of these compounds was performed by means of the combination of the DAD- and MSchromatograms: the ratio between the peak areas measured for peak $\mathrm{E}$ (the first eluting flavanonol appearing in Fig. 1A) in the DAD- and their respective EIC-chromatograms, was used as the reference value for the rest of the peak areas measured in the EIC-chromatograms at the corresponding $m / z$ values of the five groups of isomers (Fig. 1). The skin of jambolan accounted for most of the flavanonols (96.34\%) which were mainly derived from dihydromyricetin, followed by methyl- and dimethyl-dihydromyricetin derivatives. The dimethyldihydromyricetin derivatives were missing in the pulp. Flavanonols accounted for a remarkably high total amount in jambolan fruit, $174.15 \mathrm{mg} / \mathrm{kg} \mathrm{FW}$, as naringin equivalents, which was higher than the content in flavonols.

Finally, the occurrence of hydroxycinnamic acid derivatives was also investigated in the same chromatogram runs used for the analysis of flavonols, but extracting the DAD-chromatograms at $320 \mathrm{~nm}$. No peaks showing the characteristic UV spectra of hydroxycinnamic acids and their typical derivatives were found, including the well-known caftaric or chlorogenic acids which were injected as standards for possible identification.

\subsection{Condensed tannins}

Knowledge about the composition of condensed tannins in jambolan and their constituting units, namely the flavan-3-ol monomers, is very limited. The condensed tannins or proanthocyanidins of jambolan fruit have been described as only constituted of propelargonidin units (afzelechin/epiafzelechin) because of the detection of the distinct signals of $\mathrm{C4}^{\prime}$ at $157 \mathrm{ppm}$ in the ${ }^{13} \mathrm{C}$-NMR spectrum and the absence of the typical resonances corresponding to procyanidin units (catechin/epicatechin) and prodelphinidin units (gallocatechin/epigallocatechin) at 144-145 and 145-146 ppm respectively (Zhang \& Lin, 2009). However, the use of a MS method specifically developed for the analysis of flavan-3-ol monomers and proanthocyanidins in grapes and wine (Lago-Vanzela, Da-Silva, et al., 2011; Lago-Vanzela, Santos, et al., 2011; Rebello et al., 2013) allowed for the detection for the first time of flavan-3-ols different from afzelechin/epiafzelechin and propelargonidins in jambolan (Table 2). These compounds were found in relatively low concentrations, more abundantly in the skin and being the amounts of flavan-3-ol monomers lower than those of proanthocyanidins. The main types of flavan-3-ol structures were prodelphinidin units: gallocatechin among the monomers and also as the terminal units of proanthocyanidins, and gallocatechin 3-O-gallate as the main extension unit in proanthocyanidins. Therefore, the condensed tannins of jambolan could be described as prodelphinidins with a high degree of galloylation and high molecular size as indicated the high value of mDP (mean degree of polymerization), thus 
suggesting that condensed tannins do contribute to the characteristic high astringency of this fruit.

\subsection{Hydrolyzable tannins}

The hydrolyzable tannins of jambolan have been the subject of several studies. In the case of the whole fruit, the hydrolyzable tannins were identified as ellagitannins consisting of a glucose core surrounded by bonded gallic acid and ellagic acid units (Zhang \& Lin, 2009). More recently, it has been discovered that hydrolyzable tannins found in jambolan include complex molecules combining one or more constituting units like gallic acid, HHDP (hexahydroxydiphenoyl), NHTP (nonahydroxytriphenolyl), and trisgalloyl or valoneic acids (Gordon et al., 2011; Nuengchamnong \& Ingkaninan, 2009; Tong et al., 2014). The most complete published study dealing with the identification of the hydrolyzable tannin structures found in the joined edible parts of jambolan (skin and pulp were extracted together before analysis) included twelve gallotanins, one HHDP-galloyltannin and one trisgalloyldiglucose (Gordon et al., 2011). The present work is now reporting on the occurrence in the different edible parts of jambolan of thirteen gallotannins, four ellagitannins (only containing HHDP and/or NHTP groups), six HHDP-galloyltannins, two trisgalloylHHDP-tannins, together with gallic acid, ellagic acid, an ellagic acidpentoside and an unknown (not possible to suggest a likely assignment) ellagitannin (Table 3 and Fig. 3). With the exception of most gallotannins, the rest of the hydrolyzable tannins found in the edible parts of jambolan are reported for the first time in this work. As far as the authors know, vescalagin had been only reported to occur in the bark of jambolan tree (E. jambolana), used as a traditional herbal tea for the treatment of diabetes in South Asia (Tong et al., 2014), but never in the fruit. The assignment of all the latter compounds was based on spectral data obtained from the DAD UV-vis spectra (Fig. 4) and the MS and MS/MS spectra, which matched with the data obtained for some authentic standards (gallic and ellagic acids, and the ellagitannins vescalagin and castalagin) or previously reported findings (Boulekbache-Makhlouf et al., 2010; Gordon et al., 2011; Meyers et al., 2006; Nuengchamnong \& Ingkaninan, 2009; Santos et al., 2011; Tong et al., 2014; Zhu et al., 2009). The presence of trisgalloyl (valoneic acid) as a substituent was confirmed by the release of valoneic acid dilactone methyl ester after the hydrolysis of the anthocyanin-free fractions of jambolan extracts in methanolic solution (Fig. 5). In addition, it was common to find several isomers for a given structural composition among the hydrolyzable tannins.

It is very common in literature to report data on hydrolyzable tannins by the estimation of the total gallic and ellagic acids released after their hydrolysis. The analyzed samples of jambolan accounted for the following hydrolysis products in the skin and in the pulp respectively: total gallic acid, $508.27 \pm 81.92$ and $202.64 \pm 99.80 \mathrm{mg} / \mathrm{kg} \mathrm{FW}$; total ellagic acid, $76.28 \pm 8.71$ and $45.41 \pm 29.96 \mathrm{mg} / \mathrm{kg} \mathrm{FW}$; valoneic acid dilactone methyl ester (as equivalents of ellagic acid), $8.51 \pm 0.48$ and $8.65 \pm 5.70 \mathrm{mg} / \mathrm{kg}$ FW. These results suggested the predominance of gallotannins over ellagitannins, especially in the case of the skin. However, the analysis of the hydrolysis products only gives an estimate of the real content because not all hydrolyzable tannins are quantitatively hydrolyzed and several structures combine gallic acid and ellagic acid, for instance, as hydrolyzable units in the same molecule.

A more accurate analysis of the quantitative composition of the hydrolyzable tannins of jambolan was provided by the integration of the DAD-chromatograms helped by the EIC obtained at the $m / z$ values of interest (Table 4 and Fig. 3B, C and E). The total content of gallotannins was higher in the skin of jambolan and only one of the isomers of trigalloyl-glucose was not found in the pulp. The tetragalloylglucose isomers were the most abundant type of gallotannins in the skin, followed by some isomers of pentagalloyl-glucose and then mono- to trigalloyl-glucose isomers. However, in the pulp, the most abundant compound was monogalloyl-glucose followed by di- to pentagalloyl-glucose isomers. Hexagalloyl-glucose isomers were found in both skin and pulp, but they occurred as minor compounds. Ellagitannins in a strict sense, namely those compounds bearing only HHDP and NHTP substituents (vescalagin, castalagin and the two isomers of di-HHDP-glucose), accounted for important amounts in the pulp of jambolan whereas mixed ellagitannins (also bearing galloyl or trisgalloyl substituents) were the main compounds in the skin. With the exception of isomer 1 of galloyl-di-HHDP-glucose, the rest of the mixed ellagitannins composed of galloyl and HHDP substituents were missing in the pulp of jambolan, especially isomer 2 of galloyldi-HHDP-glucose and the unknown ellagitannin, which were the main individual ellagitannins found in the skin. However, the two trisgalloyl-HHDP-glucose isomers were found in both the skin and the pulp of jambolan accounting for similar amounts. In summary, the total content of ellagitannins was slightly, although not significantly, higher in the skin.

\section{Conclusions}

The main reason invoked for the use of jambolan in the treatment of various diseases and the recent interest in this fruit as raw matter for functional foods is its richness in phenolic compounds. Overall, the edible parts of jambolan accounted for 569 (skin) and 235 (pulp) $\mathrm{mg} / \mathrm{kg} \mathrm{FW}$ as gallic acid equivalents (calculated from the combined data shown in Tables 1,2 and 4), thus confirming the assumption that jambolan is a phenolic-rich fruit and, therefore, its undervalued use as food must be revised because it seems to be an excellent source of potential bioactive compounds.

For taking advantage of the bioactivity potential of jambolan a comprehensive study of the phenolic composition of its two edible parts, namely skin and pulp, was performed and revealed the occurrence of a high number of individual phenolic compounds, up to 74 , belonging to a wide variety of phenolic compound types. Around half of these individual compounds have been identified for the first time in jambolan, belonging to all the described phenolic types with the only exception of all anthocyanins and most gallotannins. The skin of the jambolan accumulated large amounts of a wide variety of phenolic compounds, with almost all of the non-tannin phenolics found therein. In contrast, condensed tannins (proanthocyanidins) and hydrolyzable tannins (gallotannins and ellagitannins) were present in both edible parts of jambolan, although they tended to account for greater amounts in the skin. The phenolic compounds found in the skin of jambolan in order of decreasing abundance were: phenolic compounds. In contrast, the pulp was mainly constituted of: gallotannins $>$ ellagitannis $>$ anthocyanins $\gg$ other phenolic compounds. These findings suggest that hydrolyzable tannins can be the main phenolic compounds responsible for the reported astringency of the edible parts of jambolan. The results also suggested the lack of hydroxycinnamic acid derivatives among the pool of phenolic compounds found in the edible parts of jambolan.

The well known profile of anthocyanins for jambolan was confirmed and was mainly based on the B-ring trisubstituted anthocyanidins. In addition, the profiles of flavonols and flavanonols were, respectively, only or mainly constituted by B-ring tri-substituted flavonoid structures. Flavanonol dihexosides have been revealed as an important constituent of the phenolic pool of jambolan. On the basis of the MS/MS spectra, two kinds of favanonol dihexosides were suggested, one with a glycosidic bond in position $\mathrm{C} 3$ of the $\mathrm{C}$-ring and the other without. In the case of flavan-3-ol monomers and proanthocyanidins, the main structures were derived from gallocatechin, another B-ring trisubstituted flavonoid. All the aforementioned results suggest that the formation of B-ring tri-substituted pattern flavonoids seems to be favored in the biosynthesis pathway of jambolan, although the biosynthesis of B-ring disubstituted flavonoids is not totally disabled in the case of anthocyanins and flavanonols. 


\section{Acknowledgments}

The authors would like to thank the Brazilian agency, CNPq, for the productivity scholarship (Da-Silva) and Project 486967/210123-CNPq. Author Rebello, L. P. G. thanks the Coordenação de Aperfeiçoamento de Pessoal de Nível Superior (CAPES) for her scholarship in the Program of Doctoral Sandwich Abroad (PDSE) and Scholarship in Country. Author Tavares, I. M. C. thanks the CAPES for her scholarships in the Program of Doctoral Sandwich Abroad (PDSE) and Scholarship in Country and to the Fundação de Amparo a Pesquisa do Estado de São Paulo (FAPESP) for her other scholarships Fapesp's Process 2013/19057-2. Author Sergio Gómez-Alonso thanks the Fondo Social Europeo and the Junta de Comunidades de Castilla-La Mancha for co-funding his contract through the INCRECYT program. Authors Gómez-Alonso, S., García-Romero, E. and Hermosín-Gutiérrez, I., thank the Spanish Ministerio de Economía y Competitividad for financial support (project AGL2011-29708-C02-02).

\section{References}

Aqil, F., Gupta, A., Munagala, R., Jeyabalan, J., Kausar, H., Sharma, et al. (2012). Antioxidant and antiproliferative activities of anthocyanins/ellagitannin-enriched extracts from Syzygium cumini L. (jamun, the Indian blackberry). Nutrition and Cancer-an International Journal, 64(3), 428-438.

Aruna, R., Prakasha, M.V.D., Abrahamb, S.K., \& Premkumara, K. (2011). Role of Syzygium cumini seed extract in the chemoprevention of in vivo genomic damage and oxidative stress. Journal of Ethnopharmacology, 134(2), 329-333.

Ayyanar, M., \& Subash-Babu, P. (2012). Syzygium cumini (L.) Skeels: a review of its phytochemical constituents and traditional uses. Asian Pacific Journal of Tropical Biomedicine, 2(3), 240-246.

Baliga, M.S., Bhat, H.P., Baliga, B.R.V., Wilson, R., \& Palatty, P.L. (2011). Phytochemistry, traditional uses and pharmacology of Eugenia jambolana Lam. (black plum): a review. Food Research International, 44(7), 1776-1789.

Bezerra, M., Araujo, A., Santos, K., \& Correia, R. (2015). Caprine frozen yoghurt produced with fresh and spray dried jambolan fruit pulp (Eugenia jambolana Lam) and Bifidobacterium animalis subsp. lactis BI-07. LWT - Food Science and Technology, 62(2), 1099-1104.

Boulekbache-Makhlouf, L., Meudec, E., Chibane, M., Mazauric, J.P., S., S., Henry, M., et al. (2010). Analysis by high-performance liquid chromatography diode array detection mass spectrometry of phenolic compounds in fruit of Eucalyptus globulus cultivated in Algeria. Journal of Agricultural and Food Chemistry, 58(24), 12615-12624.

Brito, E.S., Araújo, M.C.P., Alves, R.E., Carkeet, C., Clevidence, B.A., \& Novotny, J.A. (2007) Anthocyanins present in selected tropical fruits: acerola, jambolão, jussara, and guajiru. Journal of Agricultural and Food Chemistry, 55(23), 9389-9394.

Castillo-Muñoz, N., Gómez-Alonso, S., García-Romero, E., Gómez, M.V., Velders, A.H., \& Hermosín-Gutiérrez, I. (2009). Flavonol 3-O-glycosides series of Vitis vinifera cv. Petit Verdot red wine grapes. Journal of Agricultural and Food Chemistry, 57(1), 209-219.

Faria, A.,. A.F., Marques, M.C., \& Mercadante, A.Z. (2011). Identification of bioactive compounds from jambolão (Syzygium cumini) and antioxidant capacity evaluation in different $\mathrm{pH}$ conditions. Food Chemistry, 126(4), 1571-1578.

Gordon, A., Jungfer, E., da Silva, B.A., Maia, J.G.S., \& Marx, F. (2011). Phenolic constituents and antioxidant capacity of four underutilized fruits from the Amazon region. Journal of Agricultural and Food Chemistry, 59(14), 7688-7699.

Hassimotto, N.M.A., Genovese, M.I., \& Lajolo, F.M. (2005). Antioxidant activity of dietary fruits, vegetables, and commercial frozen fruit pulps. Journal of Agricultural and Food Chemistry, 53(8), 2928-2935.

Helmstädter, A. (2008). Syzygium cumini (L.) Skeels (Myrtaceae) against diabetes 125 years of research. Pharmazie, 63(2), 91-101.

Kaneria, M., Chanda, S., Baravalia, Y., \& Vaghasiya, Y. (2009). Determination of antibacterial and antioxidant potential of some medicinal plants from Saurashtra Region, India. Indian Journal of Pharmaceutical Sciences, 71(4), 406-412.

Kumar, A., Ilavarasan, R., Jayachandran, T., Deecaraman, M., Aravindan, P., Padmanabhan, N., et al. (2008). Anti-diabetic activity of Syzygium cumini and its isolated compound against streptozotocin-induced diabetic rats India. Journal of Medicinal Plants Research, 2(9), 246-249.

Lago, E.S., Gomes, E., \& Da-Silva, R. (2006). Produção de geleia de jambolão: processamento, parâmetros físico-químicos e avaliação sensorial da geleia. Ciência e Tecnologia de Alimentos, 26(4), 847-852.

Lago-Vanzela, E.S., Da-Silva, R., Gomes, E., García-Romero, E., \& Hermosín-Gutiérrez, I. (2011a). Phenolic composition of the Brazilian seedless table grape varieties BRS Clara and BRS Morena. Journal of Agricultural and Food Chemistry, 59(15), 8314-8323.

Lago-Vanzela, E.S., Santos, G.V., Lima, F.A., Gomes, E., \& Silva, R. (2011b). Physical-chemical, caloric and sensory characterizationof light jambolan (Syzygium cumini Lamarck) jelly. Ciência e Tecnologia de Alimentos, 31(3), 666-673.

Li, L., Adams, L.S., Chen, S., Killian, C., Ahmed, A., \& Seeram, N.P. (2009). Eugenia jambolana Lam. berry extract inhibits growth and induces apoptosis of human breast cancer but not non-tumorigenic breast cells. Journal of Agricultural and Food Chemistry, 57(3), 826-831.
Mahmoud, I.I., Marzouk, M.S.A., Moharram, F.A., El-Gindi, M.R., \& Hassan, A.M.K. (2001) Acylated flavonol glycosides from Eugenia jambolana leaves. Phytochemistry, 58(8), 1239-1244.

Meyers, K.J., Swiecki, T.J., \& Mitchell, A.E. (2006). Understanding the native Californian diet: identification of condensed and hydrolyzable tannins in Tanoak acorns (Lithocarpus densiflorus). Journal of Agricultural and Food Chemistry, 54(20), 7686-7691.

Migliato, K.F., Mello, J.C.P., Higa, O.Z., Rodas, A.C.D., Correa, M.A., Mendes-Giannini, M.J.S et al. (2010). Antimicrobial and cytotoxic activity of fruit extract from Syzygium cumini Skeels. Latin American Journal of Pharmacy, 29(5), 725-730.

Mussi, L.P., Guimarães, A.O., Ferreira, K.S., \& Pereira, N.R. (2015). Spouted bed drying of jambolão (Syzygium cumini) residue: drying kinetics and effect on the antioxidant activity, anthocyanins and nutrients contents. Food Science and Technology, 61(1), 80-88.

Nuengchamnong, N., \& Ingkaninan, K. (2009). On-line characterization of phenolic antioxidants in fruit wines from family Myrtaceae by liquid chromatography combined with electrospray ionization tandem mass spectrometry and radical scavenging detection. LWT - Food Science and Technology, 42(1), 297-302.

Omar, R., Li, L., Yuan, T., \& Seeram, N.P. (2012). $\alpha$-Glucosidase inhibitory hydrolyzable tannins from Eugenia jambolana seeds. Natural Products Journal, 75(8), 1505-1509.

Pavan Kumar, K., Prasad, P.D., Rao, A.N., Reddy, P.D., \& Abhinay, G. (2010). Antiinflammatory activity of Eugenia jambolana in albino rats. International Journal of Pharma and Bio Sciences, 1(4), 435-438.

Peixoto, M.P., \& Freitas, L.A.P. (2013). Spray-dried extracts from Syzygium cumini seeds: physicochemical and biological evaluation. Revista Brasileira de Farmacognosia, 23(1), 145-152.

Peng, S., Scalbert, A., \& Monties, B. (1991). Insoluble ellagitannins in Castanea sativa and Quercus petraea woods. Phytochemistry, 30(3), 775-778.

Rebello, L.P.G., Lago-Vanzela, E.S., Barcia, M.T., Ramos, A.M., Stringheta, P.C., Da-Silva, R. et al. (2013). Phenolic composition of the berry parts of hybrid grape cultivar BRS Violeta (BRS Rubea $\times$ IAC 1398-21) using HPLC-DAD-ESI-MS/MS. Food Research International, 54(1), 354-366.

Reynertson, K.A., Yang, H., Jiang, B., Basile, M.J., \& Kenelly, E.J. (2008). Quantitative analysis of antiradical phenols constituents from fourteen edible Myrtaceae fruits. Food Chemistry, 109(4), 883-890.

Rodrigues, K.A.F., Amorim, L.V., Dias, C.N., Moraes, D.F.C., Carneiro, S.M.P., \& Carvalho, F.A.A. (2015). Syzygium cumini (L.) Skeels essential oil and its major constituent $\alpha$ pinene exhibit anti-leishmania activity through immunomodulation in vitro. Journal of Ethnopharmacology, 160, 32-40.

Rufino, M.S.M., Alves, R.E., Fernandes, F.A.N., \& Brito, E.S. (2011). Free radical scavenging behavior of ten exotic tropical fruits extracts. Food Research International, 44(7) 2072-2075.

Sah, A.K., \& Verma, V.K. (2011). Syzygium cumini: an overview. Journal of Chemical and Pharmaceutical Research, 3(3), 108-113.

Santana, R.F., Oliveira Neto, E.R., Santos, A.V., Soares, C.M.F., Lima, Á. S., \& Cardoso, J.C (2015). Water sorption isotherm and glass transition temperature of freeze-dried Syzygium cumini fruit (jambolan). Journal of Thermal Analysis and Calorimetry, 120(1), 519-524.

Santhalakshmy, S., Don Bosco, S.J., Francis, S., \& Sabeena, M. (2015). Effect of inlet temperature on physicochemical properties of spray-dried jamun fruit juice powder. Powder Technology, 274, 37-43.

Santos, S.A.O., Freire, C.S.R., Domingues, M.R.M., Silvestre, A.J.D., \& Neto, C.P. (2011). Characterization of phenolic components in polar extract of Eucalyptus globulus Labill. bark by high-performance liquid chromatography-mass spectrometry. Journal of Agricultural and Food Chemistry, 59(17), 9386-9393.

Sari, P., Setiawan, A., \& Siswoyo, T.A. (2015). Stability and antioxidant activity of acylated jambolan (Syzygium cumini) anthocyanins synthesized by lipase-catalyzed transesterification. International Food Research Journal, 22(2), 671-676.

Sari, P., Wijaya, C.H., Sajuthi, D., \& Suprat, U. (2012). Colour properties, stability, and free radical scavenging activity of jambolan (Syzygium cumini) fruit anthocyanins in a beverage model system: natural and copigmented anthocyanins. Food Chemistry, 132(4), 1908-1914.

Sheikh, S.A., Shahnawaz, M., Nizamani, S.M., Bhanger, M.I., \& Ahmed, E. (2011). Phenolic contents and antioxidants activities in jamman fruit (Eugenia jambolana) products. Journal of Pharmacy and Nutrition Sciences, 1(1), 41-47.

Singh, J.P., Kaur, A., Shevkani, K., \& Singh, N. (2015). Influence of jambolan (Syzygium cumini) and xanthan gum incorporation on the physicochemical, antioxidant and sensory properties of gluten-free eggless rice muffin. International Journal of Food Science and Technology, 50(5), 1190-1197.

Srivastava, S., \& Chandra, D. (2013). Pharmacological potentials of Syzygium cumini: a review. Journal of the Science of Food and Agriculture, 93(9), 2084-2093.

Swami, S.B., Thakor, N.S., Patil, M.M., \& Haldankar, P.M. (2012). Jamum (Syzygium cumini $($ L. )): a review of its food and medicinal uses. Food and Nutrition Sciences, 3(8), $1100-1117$.

Tobal, T.M., Da-Silva, R., Gomes, E., Bolini, H.M.A., \& Boscolo, M. (2012). Evaluation of the use of Syzygium cumini fruit extract as an antioxidant additive in orange juice and its sensorial impact. International Journal of Food Sciences and Nutrition, 63(3), 273-277.

Tong, W.Y., Wang, H., Waisundara, V.Y., \& Huang, D. (2014). Inhibiting enzymatic starch digestion by hydrolyzable tannins isolated from Eugenia jambolana. LWT- Food Science and Technology, 59(1), 389-395.

Tupe, R.S., Kulkarni, A., Adeshara, K. m., Shaikh, S., Shah, N., \& Jadhav, A. (2015). Syzygium jambolanum and Cephalandra indica homeopathic preparations inhibit albumin glycation and protect erythrocytes: an in vitro study. Homeopathy, 104(3), 197-204. 
Veigas, J.M., Narayan, M.S., Laxman, P.M., \& Neelwarne, B. (2007). Chemical nature, stability and bioefficacies of anthocyanins from fruit peel of Syzygium cumini Skeels. Food Chemistry, 105(2), 619-627.

Zhang, L.L., \& Lin, Y.M. (2009). Antioxidant tannins from Syzygium cumini fruit. African Journal of Biotechnology, 8(10), 2301-2309.
Zhu, F., Cai, Y.Z., Xing, J., Ke, J., Zhan, Z., \& Corke, H. (2009). Rapid identification of gallotannins from Chinese galls by matrix-assisted laser desorption/ionization timeof-flight quadrupole ion trap mass spectrometry. Rapid Communications in Mass Spectrometry, 23(11), 1678-1682. 